\title{
Fracture Toughness Evaluation for Sandia Mock- up Stainless Steel Canister Weldment Using Spiral Notch Torsion Fracture Toughness Test
}




\section{DOCUMENT AVAILABILITY}

Reports produced after January 1, 1996, are generally available free via the U.S. Department of Energy (DOE) Information Bridge.

Web site http://www.osti.gov/bridge

Reports produced before January 1, 1996, may be purchased by members of the public from the following source.

National Technical Information Service

5285 Port Royal Road

Springfield, VA 22161

Telephone 703-605-6000 (1-800-553-6847)

TDD 703-487-4639

Fax 703-605-6900

E-mail info@ntis.gov

Web site http://www.ntis.gov/support/ordernowabout.htm

Reports are available to DOE employees, DOE contractors, Energy Technology Data Exchange (ETDE) representatives, and International Nuclear Information System (INIS) representatives from the following source.

Office of Scientific and Technical Information

P.O. Box 62

Oak Ridge, TN 37831

Telephone 865-576-8401

Fax 865-576-5728

E-mail reports@osti.gov

Web site http://www.osti.gov/contact.html

This report was prepared as an account of work sponsored by an
agency of the United States Government. Neither the United States
Government nor any agency thereof, nor any of their employees, makes
any warranty, express or implied, or assumes any legal liability or
responsibility for the accuracy, completeness, or usefulness of any
information, apparatus, product, or process disclosed, or represents
that its use would not infringe privately owned rights. Reference herein
to any specific commercial product, process, or service by trade name,
trademark, manufacturer, or otherwise, does not necessarily constitute
or imply its endorsement, recommendation, or favoring by the United
States Government or any agency thereof. The views and opinions of
authors expressed herein do not necessarily state or reflect those of the
United States Government or any agency thereof.




\title{
Fracture Toughness Evaluation for Sandia Mock-up Stainless Steel Canister Weldment Using Spiral Notch Torsion Fracture Toughness Test
}

\author{
Jy-An John Wang \\ Materials Science \& Technology Division \\ Oak Ridge National Laboratory \\ Program Manager \\ Bruce Bevard, John Scaglione
}

Date Published: March 2019

\author{
Prepared by \\ OAK RIDGE NATIONAL LABORATORY \\ Oak Ridge, Tennessee 37831-6283 \\ managed by \\ UT-BATTELLE, LLC \\ for the \\ U.S. DEPARTMENT OF ENERGY \\ under contract DE-AC05-00OR22725
}




\section{CONTENTS}

CONTENTS iv

LIST OF FIGURES $\quad$ v

LIST OF TABLES vii

ACKNOWLEDGMENTS $\quad$ ix

ABSTRACT

1. INTRODUCTION 1

1.1 Background 1

1.2 The Origin of The Received Sandia Mockup Canister Weldment 1

1.3 Proposed SNTT Sample Preparation and As-received Weldment Microscopic Examinations 4

2. ORNL SPIRAL NOTCH TORSION FRACTURE TESTING TECHNOLOGY 10

$\begin{array}{lll}2.1 \text { Introduction } & 10\end{array}$

$\begin{array}{lll}2.2 & \text { Spiral Notch Torsion Test Methodology } & 10\end{array}$

2.3 The Evolution of SNTT Compliance and Fracture Resistance for Ductile Materials 12

2.4 Experimental Verification on the Developed SNTT Fatigue Crack Compliance Protocol 16

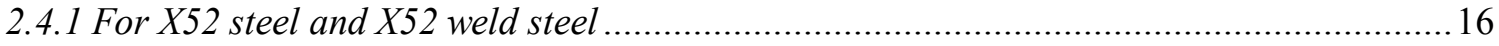

2.4.2 Validation using 12 L14 carbon steel and SS304/308 weld steel materials.................... 17

3. SS304/308 WELD SNTT SAMPLE PREPARATION AND BIAXIAL TESTER SET-UP 19

$\begin{array}{lll}3.1 & \text { SNTT Specimens Designs and Configurations } & 19\end{array}$

$\begin{array}{ll}3.2 & \text { SS304/308 Weld SNTT Sample Fixture Design Configuration } \\ 20\end{array}$

$\begin{array}{lll}3.3 & \text { SNTT Equipment Setup } & 21\end{array}$

4. SANDIA SS304/308 WELD FRACTURE TOUGHNESS EVALUATION 23

4.1 SNTT Testing on SS304/308 Weld Steel Material 23

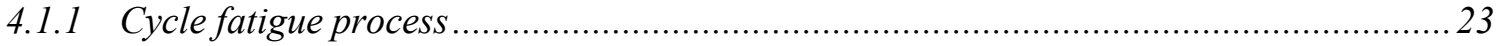

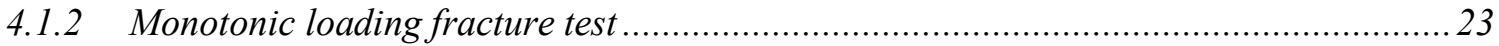

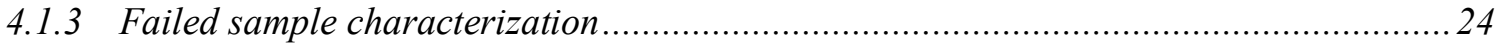

4.1.4 SNTT 304/308 weld samples fracture test results .....................................................25

4.2 Fracture Toughness Evaluation on the Tested SNTT HAZ and Weld Samples 27

4.2.1 SNTT finite element modeling methodology for ductile materials .................................27

4.2.2 FEM analyses and energy release rate evaluation for SNTT HAZ-1 specimen test results. 27

4.2.3 FEM analyses and energy release rate evaluation for SNTT Weld-10 specimen test results

4.2.4 FEM analyses and energy release rate evaluation for SNTT Base-1 specimen test results 29

5. CONCLUSIONS 



\section{LIST OF FIGURES}

Figure

Page

Figure 1 The schematic diagram of the physical location of the received weldment, the axial weldment sample was used in neutron residual stress mapping study indicted with a purple arrow marker. [1] ...........2

Figure 2 Mockup container before being sectioned. (a) Location of these sections into which container was cut - one for residual stress analyses (A) and two for specimens (B and C). A temporary spider (b) was placed just below the cut made between sections A and B to minimize distortion as the cut was made. [1]

Figure 3 Location of surface strain gage positions along the longitudinal and circumferential welds as well as the position of temporary mounting blocks welded to the base of the container that facilitated positioning while the cuts were being made. [1]

Figure 4 Cross section of a longitudinal weld. Note that the outer diameter FZ passes well into the initial weld made on the inner diameter. Also note that the final weld passes were sometimes offset from the centerline of the weldment, yielding an asymmetric appearance.[1] ......................................... 3

Figure 5 Dimensions of the received weld plate sectioned from Sandia full scale mockup SNF storage canister. Weld fusion region is about $28 \mathrm{~mm}$ shown located in the middle of the weld plate. ........................ 4

Figure 6 Etching surface of the received weld sample shows detailed FZ boundary and weld texture profile. ..4 Figure 7 Detailed texture profiles at weld FZ, HAZ, and Base regions at different weld bead's areas, from Areas-A to Area-M regions. Very clear distinction boundary was shown at FZ and Base/HAZ

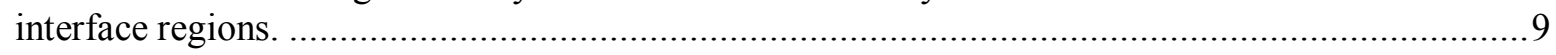

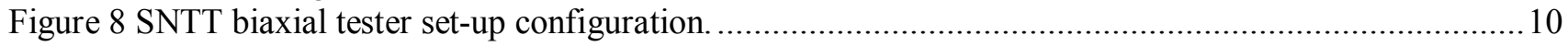

Figure 9 Fractured SNTT specimens: (a) A302B, and (b) A533B miniature sample. ................................ 10

Figure 10 (a) Schematic of SNTT theory, (b) CT and SNTT specimens comparison and CT specimen size effect. .....

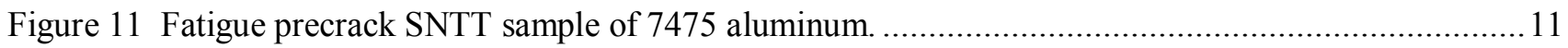

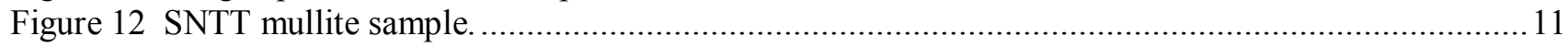

Figure 13 (a) The evolution of crack growth in the SNTT sample with FEA simulation models. (b) Single crack depth example FEA displacement results, for $\mathrm{a} / \mathrm{D}=0.10, \mathrm{D}=0.375$-inch, Steel, under end rotation theta $=0.002$ with ends fixed at $\mathrm{U} 1$ and $\mathrm{U} 2$ orientations.

Figure 14 (a) The unscaled compliance evolution with the crack growth; (b) The scaled compliance evolution along the crack growth with unbroken ligament factor.

Figure 15 (a) The unscaled energy release rate evolution with the crack growth; (b) The scaled energy release rate evolution along the crack growth with unbroken ligament factor....

Figure 16 The failed B2 specimen of X52 baseline sample, (a) entire view; (b) enlarged view of the middle section of tested SNTT sample, (c) the fatigue pre-crack growth profile of X52 weld SNTT sample W2, where the crack growth orientation is toward the central axis of the SNTT sample................17

Figure 17 Fatigue-precrack fractured SNTT samples of 12L14 carbon steel, at different target fatigue crack growth length, (a) crack initiation sample, (b) deep penetration fatigue pre-crack sample, (c) relative shallow pre-crack sample, (d) two consecutive fatigue pre-crack stages sample. The red arrow is pointed at the fatigue pre-crack front.

Figure 18 Fatigue-pre-crack fractured SNTT samples of 304/308 weld steel, at different target fatigue crack growth length, (a) sample with deep fatigue pre-crack initiation, (b) relatively deep penetration fatigue pre-crack sample with crack jump, (c) sample with fatigue pre-crack running through the sample cross-section, (d) fractured SNTT sample with deep spiral notch and relatively shallow fatigue pre-crack. The red arrow is pointed at the fatigue pre-crack front. .................................. 18

Figure 19 Geometry details of the SS304/308 weld steel SNTT specimen. ........................................... 19

Figure 20 SNTT specimens with different spiral groove designs, (Top) single loop spiral groove with 0.0375 " notch depth, (Middle) single loop with 0.100" notch depth, (Bottom) two loops with 0.1125 " notch depth.

Figure 21 SNTT weld sample machining physical location in the as-received Sandia weldment. .................20 
Figure 22 SNTT weld sample machining physical location in the as-received Sandia weldment..................20

Figure 23 Schematic for fixture to adapt the 304/308 weld SNTT specimen..........................................21

Figure 24 Schematic for base to adapt the SS304/308 weld SNTT fixture...........................................21

Figure 25 SNTT biaxial tester set-up, sample installation, and the final fracture test...............................22

Figure 26 HAZ-1 test results, (Left) upon sudden failure a significant shock reaction was observed, (Right) The slopes of different loading and unloading sequences does not change, indicate no crack growth during the monotonic loading, the specimen undergo significant non-linear deformation before final failure, at $56 \mathrm{~N}-\mathrm{m}$ (495 Lbf-in) fracture torque.

Figure 27 2-loop Weld-4 test results, (Left) upon sudden failure a significant shock reaction was observed, (Right) The slopes of different loading and unloading sequences does not change, indicate no crack growth during the monotonic loading, the specimen undergo significant non-linear deformation before final failure, at $41 \mathrm{~N}-\mathrm{m}$ (362.8 Lbf-in) fracture torque.....................................................22

Figure 28 SNTT HAZ-1 fracture specimen and the associated fracture surface profile...............................24

Figure 29 SNTT 2-loop Weld-10 fracture specimen and the associated fracture surface profile. .................24

Figure 30 (Left) Most SNTT weld 1-loop shallow-notch specimens' failures are initiated at HAZ regions, (Right) All the weld 2-loop deep-notch specimens are failed at HAZ regions. .............................25

Figure 31 SNTT Weld-9 specimen fracture test results, (Left) Torque vs. angle data, and (Right) Upon failure significant axial load shock was observed, reaching magnitude of $\sim 1800 \mathrm{~N}$..............................26

Figure 32 (Left) Typical finite element models used for ductile material fracture toughness characterization, due to high ductility of the 304/308 weld material, the singular wedge element with quarter-node element was relaxed back to normal wedge element with middle-node element; (Right) Typical FEM analyses results that indicate tri-axial tensile stress at near crack tip and butterfly plastic process zone around the crack tip, which indicate a high geometry constraint toughness testing configuration.

Figure 33 Finite element model for SNTT HAZ-1 specimen test simulation. .........................................28

Figure 34 (Left) Full model FEM deformation and von-Miss stress profile, (Right) Deformation and von Miss stress profiles at the middle layer of finite element model.......................................................28

Figure 35 Finite element model for SNTT Weld-10 specimen test simulation.........................................29

Figure 36 (Left) Full model FEM deformation and von-Miss stress profile, (Right) Deformation and von Miss stress profiles at the middle layer of finite element model.

Figure 37 Finite element model for SNTT Base-1 specimen test simulation.

Figure 38 (Left) Full model FEM deformation and von-Miss stress profile, (Right) Deformation and von Miss stress profiles at the middle layer of finite element model, where significant crack front blunting was observed. 


\section{LIST OF TABLES}

\section{Table}

Page

Table 1 Composition of the 304L plate and 308L filler metal used for construct mockup. .............................

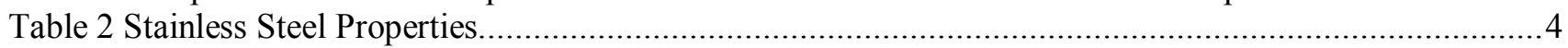

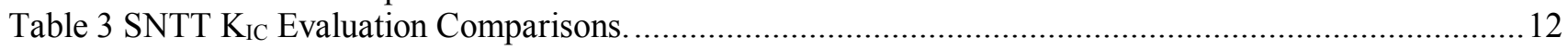

Table 4 SNTT 304/308 weld specimens fracture test results ...........................................................25

Table 5 Summary of fracture toughness obtained from SNTT test and CT test results ............................... 31 


\section{ACKNOWLEDGMENTS}

This research was sponsored by the Spent Nuclear Fuel Canister Program of the US Department of Energy and was carried out at Oak Ridge National Laboratory under contract DE-AC05-00OR22725 with UT-Battelle, LLC.

The authors would like to thank Program Managers Bruce Bevard and John Scaglione for providing guidance and support to this project, Charles Bryan of Sandia National Laboratory for providing weldment samples, Tom Geer for preparing weld etching sample and the associated weld texture micrographs, Lianshan Lin and Hong Wang for reviewing the report, and Sandy McPherson for providing editorial review. 



\begin{abstract}
Many radioactive materials within the nuclear fuel cycle present a significant hazard. Such materials include spent nuclear fuel, high-level waste, legacy waste and other nuclear materials that have no current outlet than storage. These materials are often held in long-term storage as an interim stage within their lifecycle. Lifecycles can include reuse or disposal. Safety and security of spent nuclear fuel (SNF) interim storage installations are very important, due to a great concentration of fission products, actinides and activation products. Stress corrosion cracking of interim storage containers has been identified as a high priority data gap by the Department of Energy. However, little has been done with regards to the canister weld material properties, including the fracture toughness, and their impact on stress corrosion, until recently from Sandia National Laboratory canister mockup program. Furthermore, because no post-weld heat treatment was required, the associated high tensile residual stress within these canister welds can drive the initiation and growth of stress corrosion cracking (SCC) cracks. Thus, the fracture mechanical property, such as fracture toughness, is an essential information to understand the canister weldment fracture resistance behavior and to support mitigation protocol development to counter SCC. In this work, we carried out fracture toughness evaluation on the received mock-up canister weldments from Sandia, using spiral notch torsion fracture test technology. The details of the weldment fracture toughness evaluation program development at ORNL are presented in this progress report.
\end{abstract}

The objective of this research is to collect fracture toughness data on the mock-up canister weldment from Sandia National Laboratory. Data will be collected under quasi-static fracture loading using the Oak Ridge National Laboratory (ORNL) developed Spiral Notch Torsion Test (SNTT) technology carried out on a biaxial tension/torsion tester. These data will be used to support the ongoing SNF dry storage canister modeling activities and to address regulatory issues associated with canister container integrity and the follow-on SNF system transport reliability.

SNTT has been a recent breakthrough in measuring fracture toughness for different materials, including metals, ceramics, concrete and polymers composites. Due to its high geometry constraint and unique loading condition, SNTT can be used to measure the fracture toughness with smaller specimens without concern of size effects. The application of SNTT to brittle materials has been proved to be successful. The micro-cracks induced by original notches in brittle materials could ensure crack growth in SNTT samples. Therefore, no fatigue precracks are needed. The application of SNTT to the ductile material to generate valid toughness data will require a test sample with sufficient crack length to increase the sample fracture tip localized constraint. Fatigue precrack growth techniques are employed to introduce sharp crack front into the sample. Previously, only rough calculations were applied to estimate the compliance evolution in the SNTT crack growth process; while accurate quantitative descriptions have never been attempted. This generates an urgent need to understand the crack evolution during the SNTT fracture testing process of ductile materials. The newly developed governing equations for SNTT crack growth estimate are used to control the fatigue crack growth to effectively reaching the target crack length. The detailed SNTT approach and its estimated fracture toughness for the as-received Sandia canister weldment and the associated baseline 304 stainless steel are presented in this report.

In the past SNTT technology has also been successfully applied to investigate the fracture behavior of X52 and X80 steels and the X52 welded materials used for hydrogen infrastructures. The current study in supporting Sandia SNF Dry Storage Mock-up Canister Program is the first attempt of applying SNTT to the highly ductile stainless steel and the associated weld materials. The SNTT test results indicate that SNTT method is a reliable test approach with good repeatability in applying to SS304 steel and SS304/308 weld material. The estimate $\mathrm{J}_{\mathrm{Q}}$ upon fracture for the baseline SS304 steel is at $1618 \mathrm{lb} / \mathrm{in}$. The estimate $\mathrm{J}_{\mathrm{Q}}$ upon fracture for the SS304/308 weld from HAZ and weld specimens are $720 \mathrm{lb} /$ in and $850 \mathrm{lb} /$ in, respectively. 


\section{INTRODUCTION}

\subsection{Background}

Many radioactive materials within the nuclear fuel cycle present a significant hazard. Such materials include spent nuclear fuel, high-level waste, legacy waste and other nuclear materials that have no current outlet other than storage. These materials are often held in long-term storage as an interim stage within their lifecycle. Lifecycles can include reuse or disposal. Safety and security of spent nuclear fuel (SNF) interim storage installations are very important, due to a great concentration of fission products, actinides and activation products. Stress corrosion cracking of interim storage containers has been indicated as a high priority data gap by the Department of Energy. However, little has been done regarding the canister weld material properties, including weldment fracture toughness, and their impact on stress corrosion, until recently with Sandia canister mockup program [1]. In this work, we carried out fracture toughness evaluation on the received mock-up canister weldments from Sandia, using ORNL spiral notch torsion fracture test (SNTT) technology.

SCC of interim storage containers has been identified as a high priority data gap by the Nuclear Waste Technical Review Board [2], Department of Energy [3], the Nuclear Regulatory Commission [4,5], and the Electric Power Research Institute [6]. Uncertainties exist both in the understanding of the environmental conditions on the surface of the storage canisters and in the textural, microstructural, and electrochemical properties of the storage containers themselves. For an SCC crack to initiate, the tensile stresses in the metal must be of a sufficiently large magnitude that the threshold stress intensity value at a potential nucleation site is exceeded. The canister surface environment and the associated residual stress profiles have been evaluated by Sandia and EPRI $[1,7,8]$, however, more needs to be done to assess canister material properties and their impact on corrosion. Of specific interest are regions associated with the welds on the canisters, because the welding process modifies the microstructure of the stainless steel as well as its resistance to localized corrosion. In addition, welding introduces high tensile residual stresses that can drive the initiation and growth of SCC cracks.

To meet the need for additional data on the canister material properties, the DOE Used Fuel Disposition campaign program has procured a full-diameter cylindrical mockup of a dual certified 304/304L stainless steel (SS) storage canister produced using the same manufacturing procedures as fielded SNF fuel interim storage canisters. ORNL recently received five such weld plates, three longitudinal welds and two circumferential welds. High residual tensile stresses may be present in the metal, due to cold working or welding. Weld residual stresses (WRS) are generally the most important component, and are a function of many factors, including weld geometry, sample thickness, welding speed, number of passes, inter-pass temperatures, and base metal properties relative to the weld. Because of this, WRS are specific to the geometry and welding processes used and can only be measured from an actual storage canister or a mockup made using the same procedures as the real canisters. While the residual stresses were anticipated to be largest in the weld fusion zone (FZ), the regions surrounding the weld (the HAZ) are the regions where localized corrosion is most likely to initiate due to sensitization resulting from the thermal profile associated with the welding process. Characterization of the stresses in the HAZ can be accomplished by performing neutron scattering measurements approximately $4 \mathrm{~mm}$ from the weld toe (i.e., edge of the weld FZ).

\subsection{The Origin of The Received Sandia Mockup Canister Weldment}

The received canister weldment samples are from the top portion of the Cut B section, as shown in Figure 1 with purple arrow marker. The picture of the associated Sandia mockup canister and the marked cut sections of A, B, and C is shown in Figure 2, where Section A is for residual stress analyses, B section is for weld samples, and $\mathrm{C}$ section is for NDE evaluation. The details of strain gages locations in Section A are shown in Figure 3. 


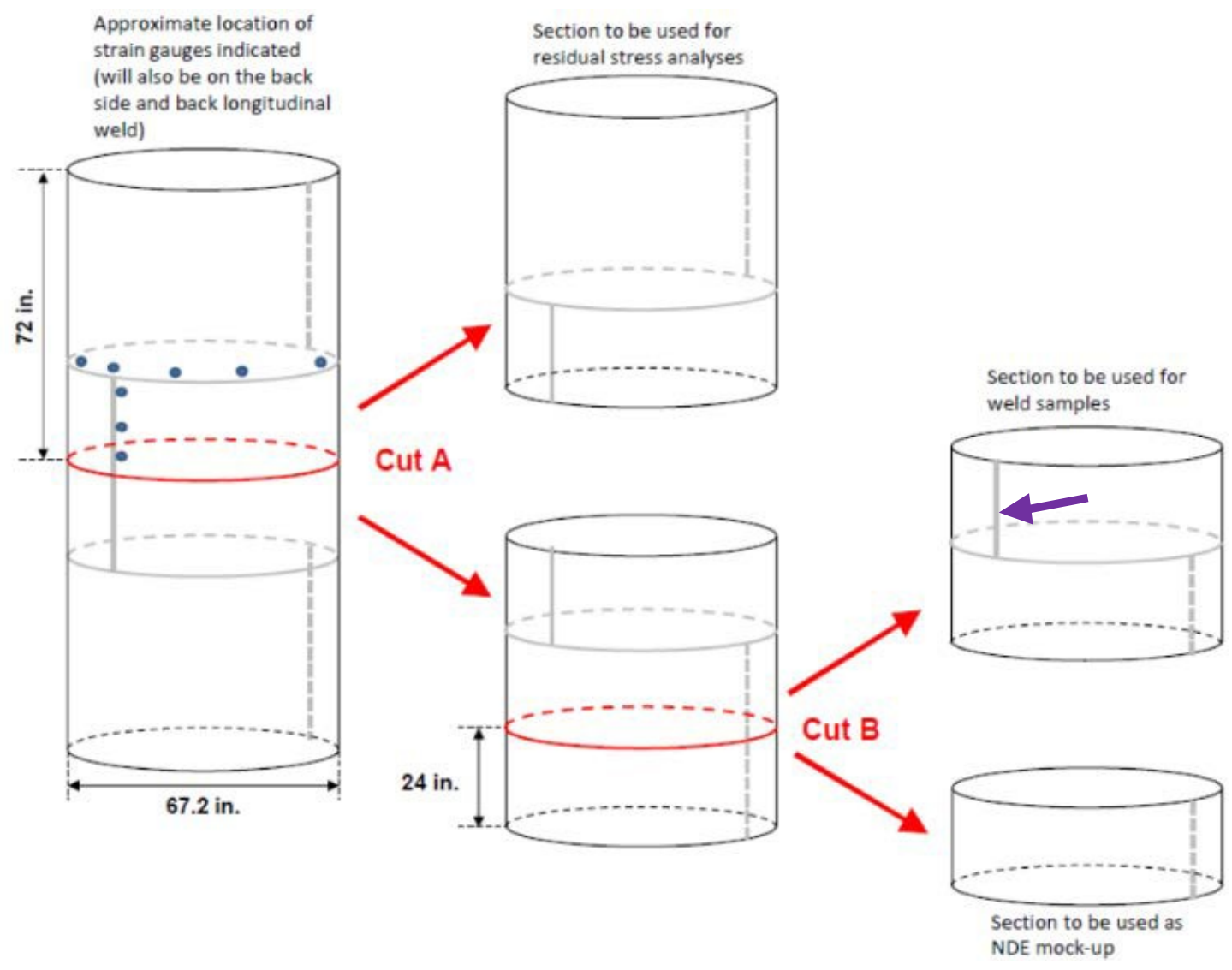

Figure 1. The schematic diagram of the physical location of the received weldment, the axial weldment sample was used in neutron residual stress mapping study indicted with a purple arrow marker. [1]
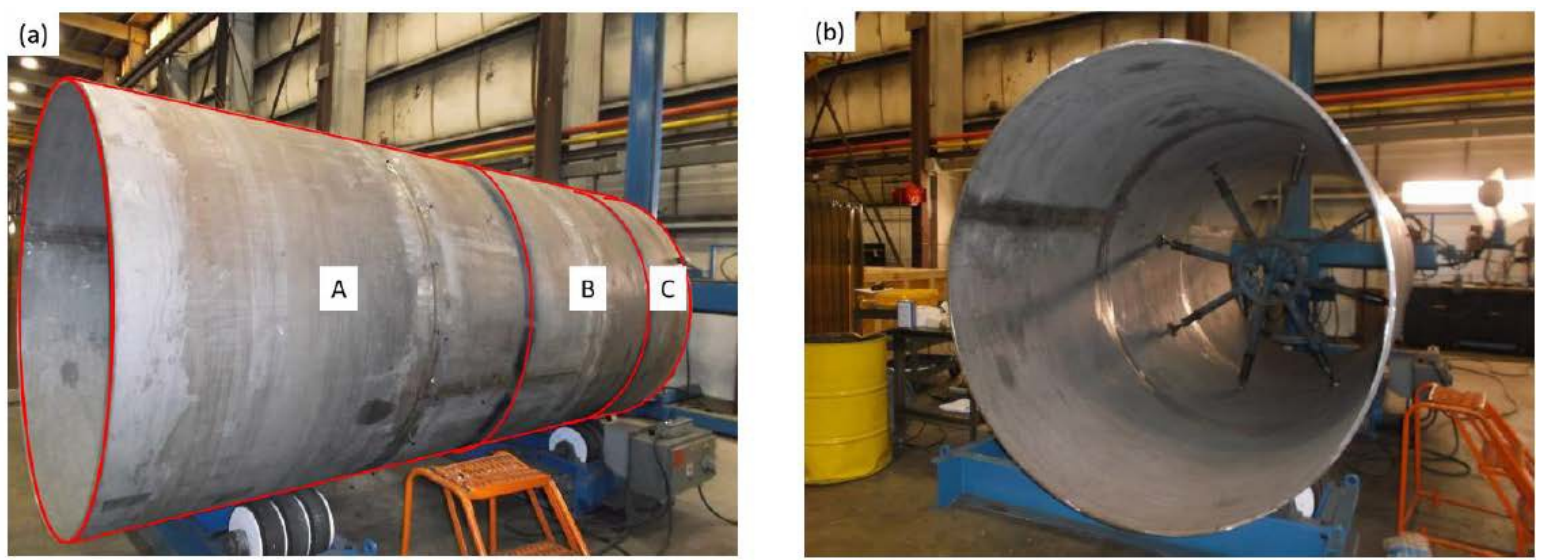

Figure 2. Mockup container before being sectioned. (a) Location of these sections into which container was cut -one for residual stress analyses $(A)$ and two for specimens (B and $C$ ). A temporary spider (b) was placed just below the cut made between sections $A$ and $B$ to minimize distortion as the cut was made. [1] 


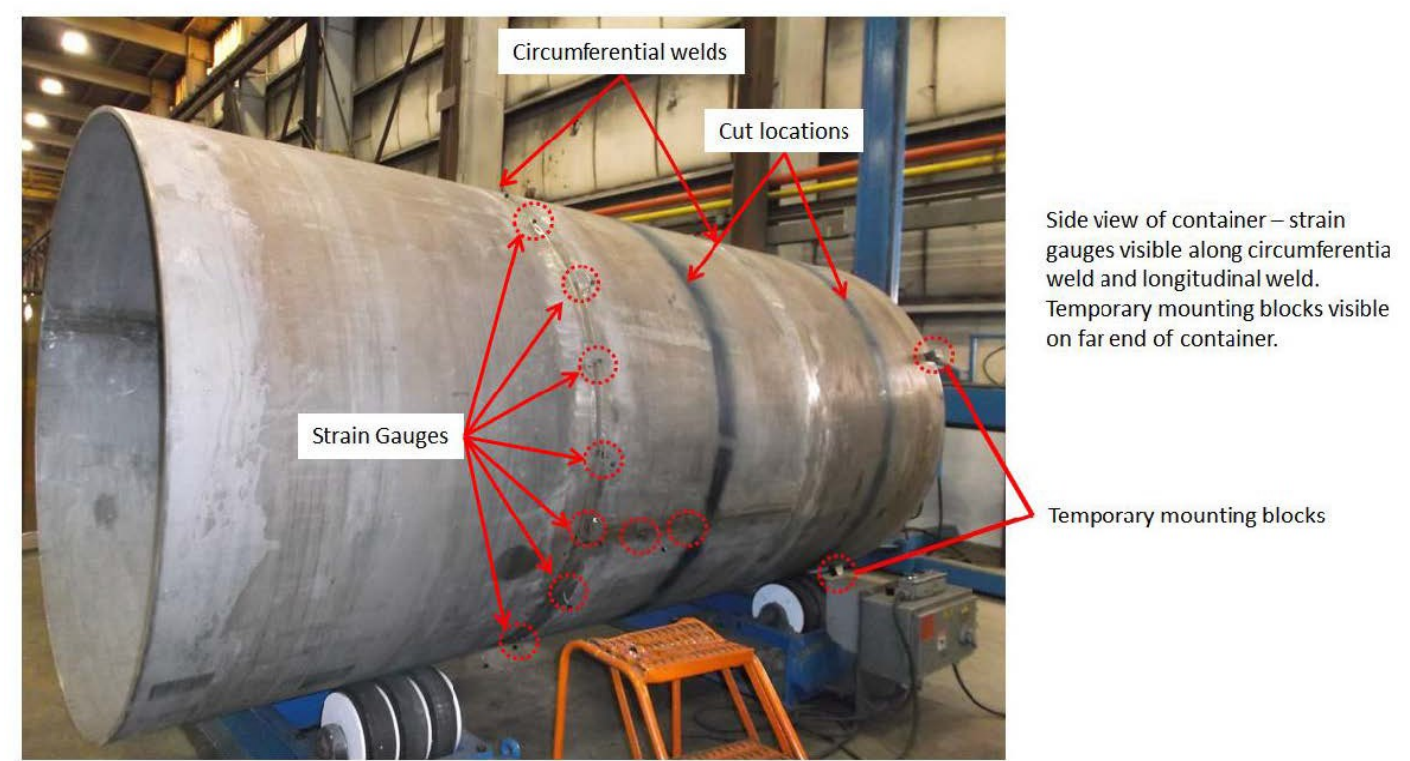

Figure 3. Location of surface strain gage positions along the longitudinal and circumferential welds as well as the position of temporary mounting blocks welded to the base of the container that facilitated positioning while the cuts were being made. [1]

The compositions of the 304/304L SS plates and the 308L SS filler material used to build the mockup canister are listed in Table 1 below. All the welds of the mockup canister were formed via the submergedarc welding (SAW) process with multi-pass welds. [1]

Table 1. Composition of the $304 \mathrm{~L}$ plate and $308 \mathrm{~L}$ filler metal used for construct mockup.

\begin{tabular}{|c|c|c|c|c|c|c|c|c|c|c|c|}
\hline & C & Co & $\mathrm{Cr}$ & $\mathrm{Cu}$ & $M n$ & Mo & $\mathrm{N}$ & $\mathrm{Ni}$ & $P$ & $\mathbf{s}$ & $\mathbf{S i}$ \\
\hline $\begin{array}{l}\text { Plate Material } \\
\text { (304/304L) }\end{array}$ & 0.0223 & 0.1865 & 18.1000 & 0.4225 & 1.7125 & 0.3180 & 0.0787 & 8.0270 & 0.0305 & 0.0023 & 0.2550 \\
\hline $\begin{array}{l}\text { Weld Filler } \\
\text { (308L) (lot 1) }\end{array}$ & 0.014 & -- & 19.66 & 0.16 & 1.70 & 0.11 & 0.058 & 9.56 & 0.025 & 0.010 & 0.39 \\
\hline $\begin{array}{l}\text { Weld Filler } \\
\text { (308L) (lot 2) }\end{array}$ & 0.012 & -- & 19.71 & 0.192 & 1.730 & 0.071 & 0.053 & 9.750 & 0.024 & 0.012 & 0.368 \\
\hline
\end{tabular}

The inner diameter was welded first, followed by the outer diameter. Once the inner diameter weld was made, the edge preparation for the outer diameter weld was made by arc-gouging along the parting line between the two plates being welded together. A representative cross-sectional image of a circumferential weld is presented in Figure 4 below.

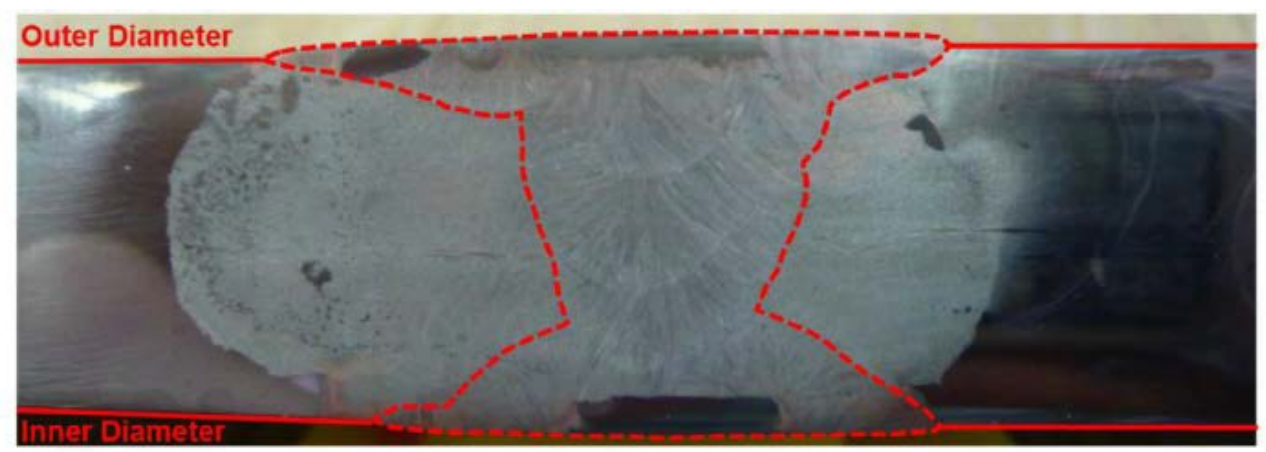

Figure 4. Cross section of a longitudinal weld. Note that the outer diameter FZ passes well into the initial weld made on the inner diameter. Also note that the final weld passes were sometimes offset from the centerline of the weldment, yielding an asymmetric appearance.[1] 
The tensile properties of the 304, 304L, 308L SS plates, and SS304/308 weld materials are stated in Table 2. $[9,10]$

Table 2 Stainless Steel Properties

\begin{tabular}{|c|c|c|c|}
\hline Type & $\begin{array}{c}\mathrm{E} \\
{[\mathrm{GPa}]}\end{array}$ & $\begin{array}{c}0.2 \% \text { Yield } \\
\text { stress [MPa] }\end{array}$ & $\begin{array}{c}\text { UTS } \\
{[\mathrm{MPa}]}\end{array}$ \\
\hline 304 & 195 & 241 & 586 \\
\hline $304 \mathrm{~L}$ & 195 & 207 & 552 \\
\hline $308 \mathrm{~L}$ & 195 & 207 & 551 \\
\hline $304 / 308$ SAW & 195 & 380 & 565 \\
\hline
\end{tabular}

\subsection{Proposed SNTT Sample Preparation and As-received Weldment Microscopic Examinations}

In this work, we propose to evaluate the fracture toughness profiles of received canister weldments, where the SNTT weld samples were machined through the base metal, weld FZ, and HAZ regions within the weld plate as shown in Figure 5. Sample area far away from the weld FZ and HAZ will be taken as baseline to estimate base 304SS fracture toughness. The etching surface profile of the weld sample is shown in Figure 6, and the detailed texture profiles of the weld beads from Area-A to Area-M regions are shown in Figure 7.
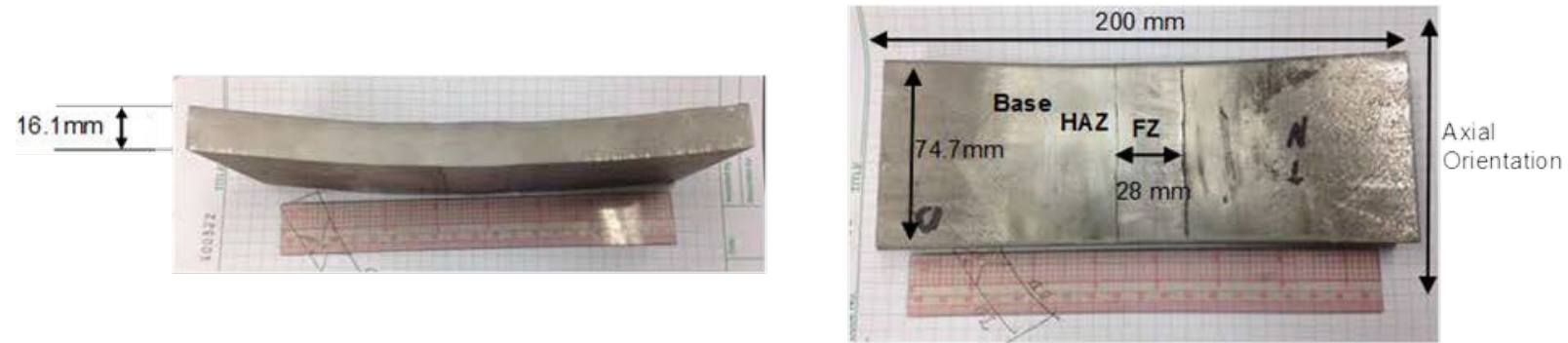

Figure 5. Dimensions of the received weld plate sectioned from Sandia full scale mockup SNF storage canister. Weld fusion region is about $28 \mathrm{~mm}$ shown located in the middle of the weld plate.

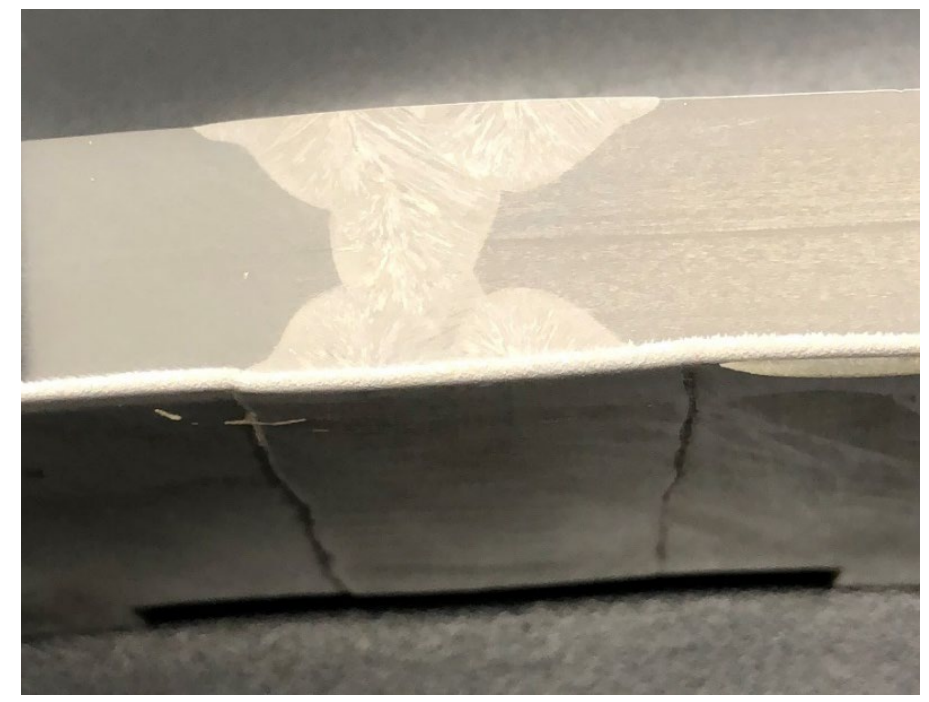

Figure 6. Etching surface of the received weld sample shows detailed FZ boundary and weld texture profile. 

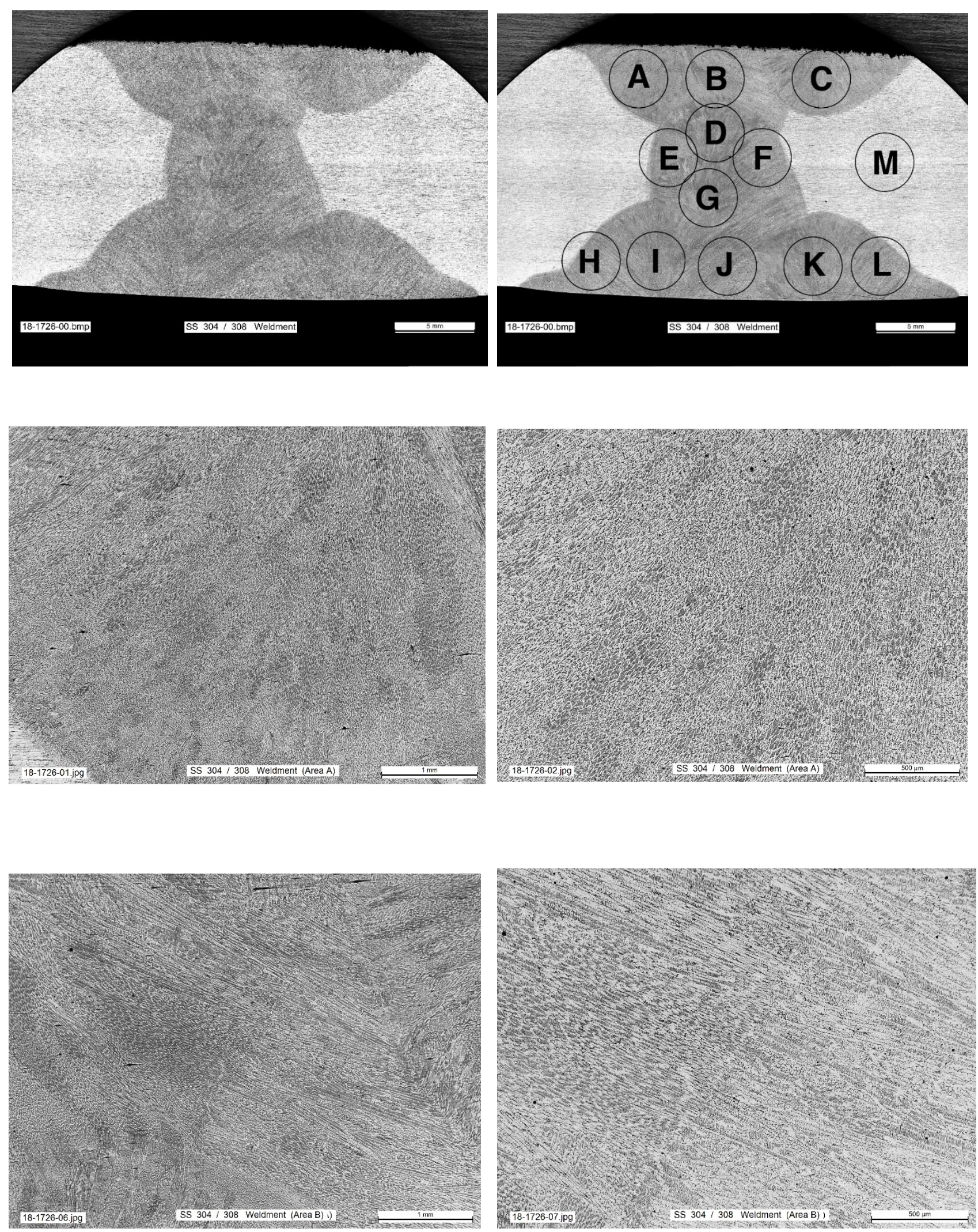

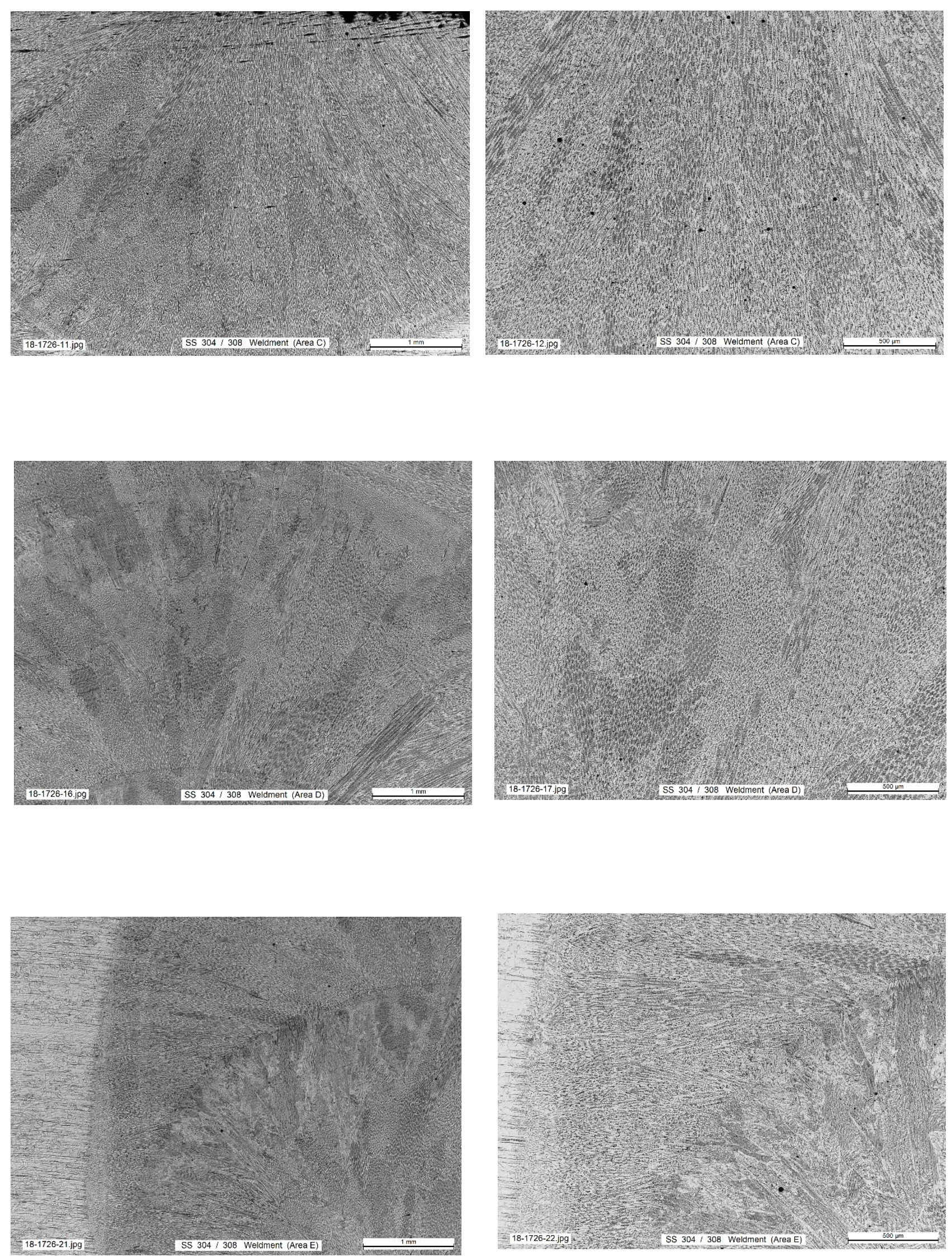

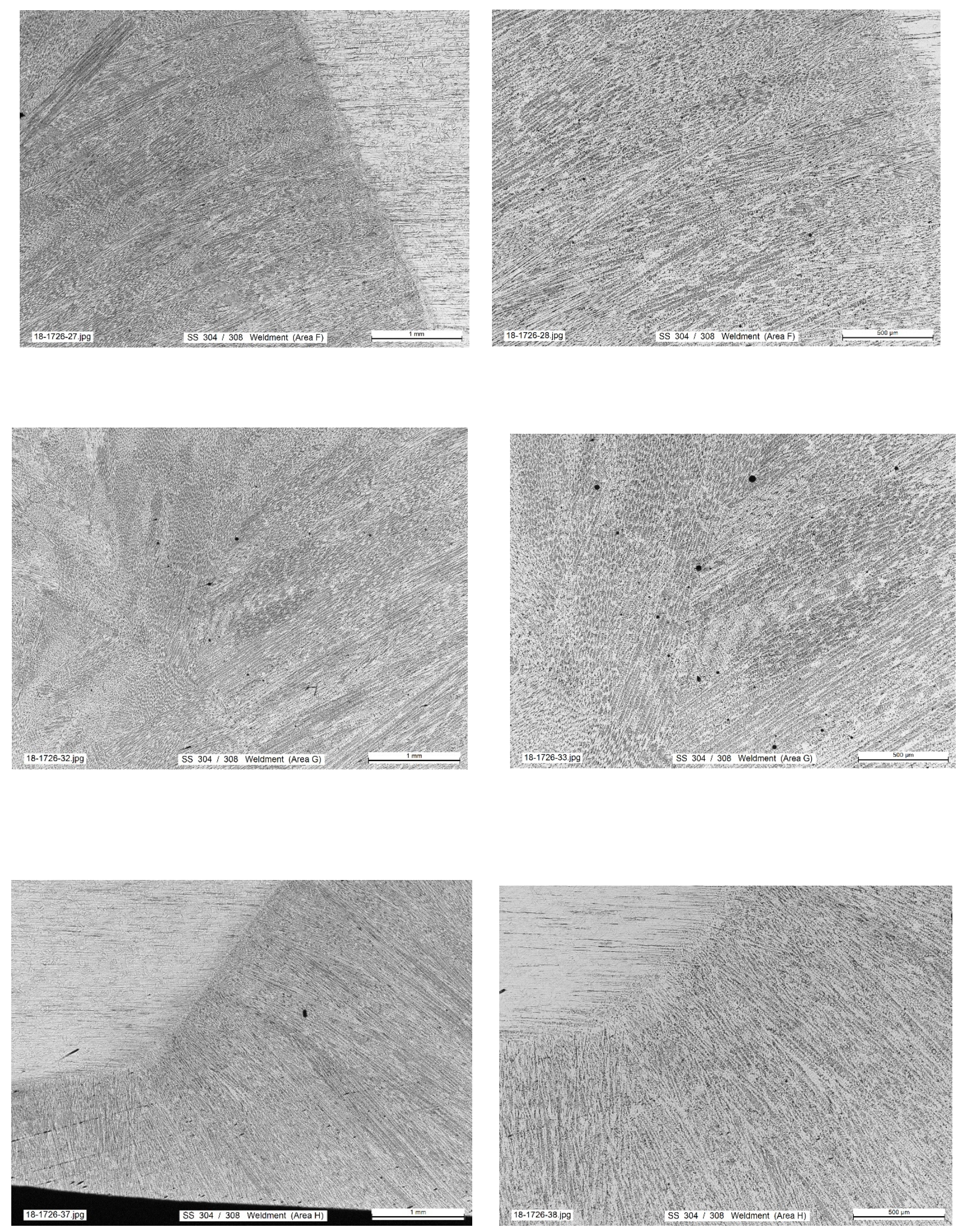

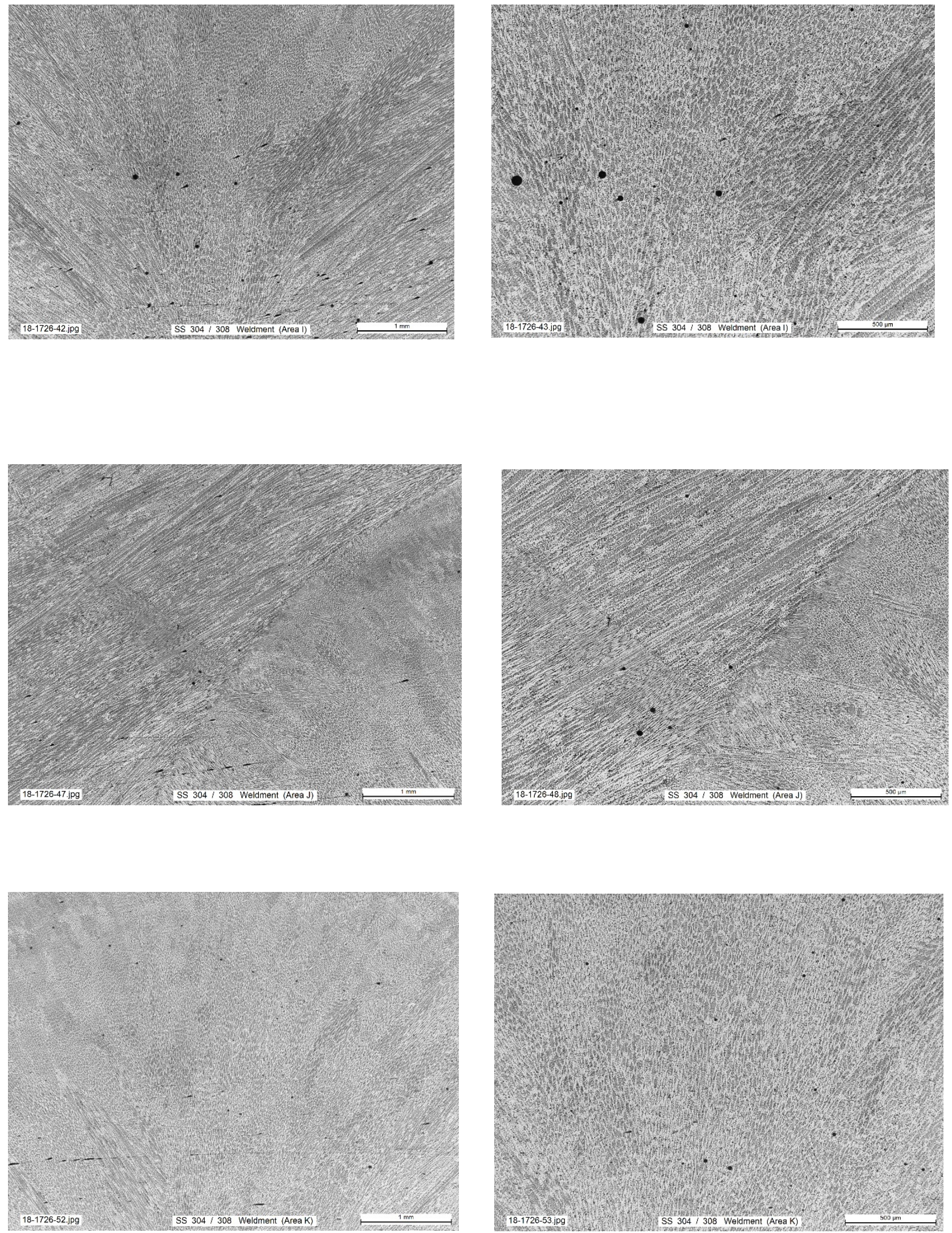

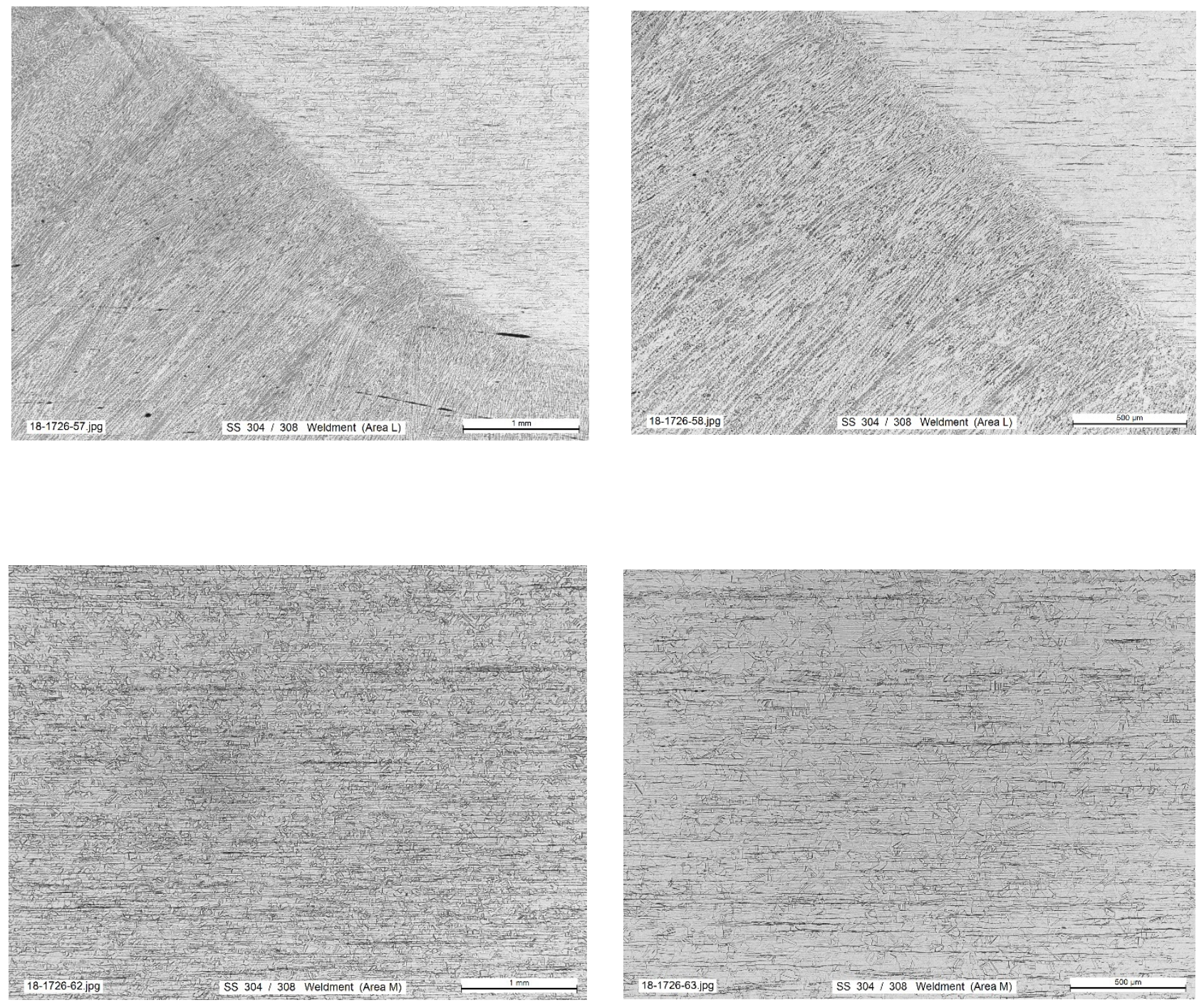

Figure 7. Detailed texture profiles at weld FZ, HAZ, and Base regions at different weld bead's areas, from Areas-A to Area-M regions. Very clear distinction boundary was shown at FZ and Base/HAZ interface regions. 


\section{ORNL SPIRAL NOTCH TORSION FRACTURE TESTING TECHNOLOGY}

\subsection{Introduction}

A basic postulate of fracture mechanics is the existence of a flaw that raises the local stress level in the material and produces fracture when the stress level reaches a critical value. The measure of fracture toughness is represented in terms of stress-intensity factor. The Mode I (tensile opening mode) stress-intensity factor at the onset of rapid crack propagation under plane-strain conditions is defined as fracture toughness, $K_{\text {IC }}$, a controlling reference parameter used in design to avoid catastrophic brittle fracture. ASTM standard test methods, Standard Test Method for Plane-Strain Fracture Toughness of Metallic Materials (E399), are widely used to determine fracture toughness of metallic materials, using compact tension (CT) and compact disk tension specimens having thickness and volume sufficient to ensure the plane-strain condition at the crack front. Therefore, the accuracy and reliability of test results may be questionable if the specimen becomes excessively smaller than the minimum specimen size recommended by ASTM standard. If it is not possible to make a specimen from the available material that meets the criteria specified in E399, then it is not possible to make a valid $K_{\mathrm{IC}}$ measurement according to E399. Meeting the requirements is difficult and impractical because engineering systems materials to be investigated may be geometrically unsuitable and/or have insufficient volume for making the standard specimen. Therefore, use of small specimens for $K_{\mathrm{IC}}$ measurement is essential for application to engineering structure safety evaluation under target service environment. Clearly, there is a need for a new method to obtain valid data using small samples. Despite the international efforts on the development of small specimen testing techniques, no methods currently exist for direct measurement of $K_{\text {IC }}$ for small specimens without concern for size effect. Unlike the conventional test methods, the spiral notch torsion test (SNTT) method is capable of testing small rod specimens that bear no resemblance to conventional compact tension specimens nor using conventional mode of loading [11-16]. Therefore, the SNTT method is unique and innovative in both specimen design and

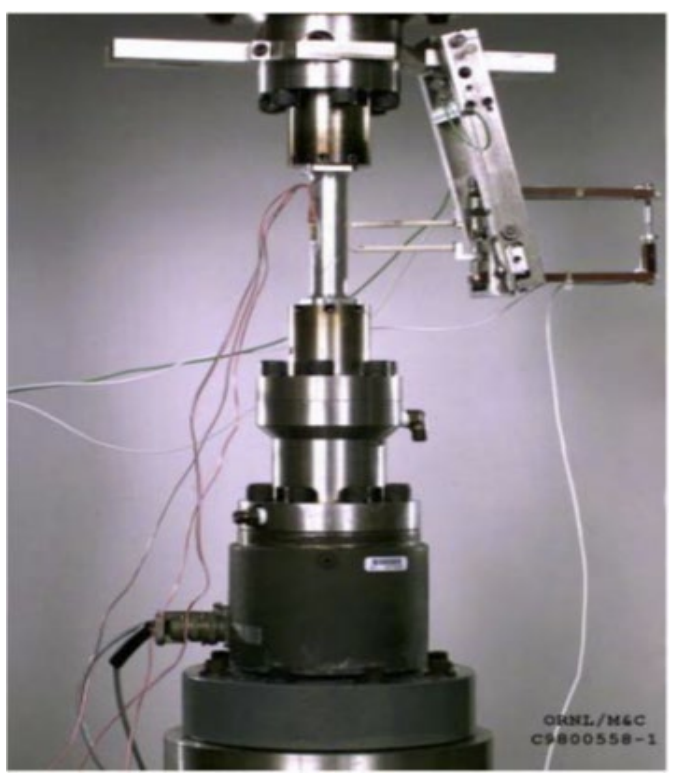

Figure 8. SNTT biaxial tester set-up configuration. loading concept.

\subsection{Spiral Notch Torsion Test Methodology}

The SNTT system, shown in Figure 8, was developed to measure the intrinsic fracture toughness $\left(K_{\text {IC }}\right)$ of structural materials, overcomes many of the limitations inherent in traditional techniques, and introduces new possibilities for standardizing fracture toughness testing using small or miniature specimens. The system is uniquely suited to test a wide variety of materials, such as metals and alloys, ceramics, composites, thin-film coating, polymers, and concrete [17-22], and for pressure vessel steel in-situ hydrogen embrittlement study [23-24]. The SNTT system operates by applying pure torsion to cylindrical specimens machined with a notch line that spirals around the specimen at a $45^{\circ}$ pitch. The fractured miniature SNTT specimen is shown in Figure 9.

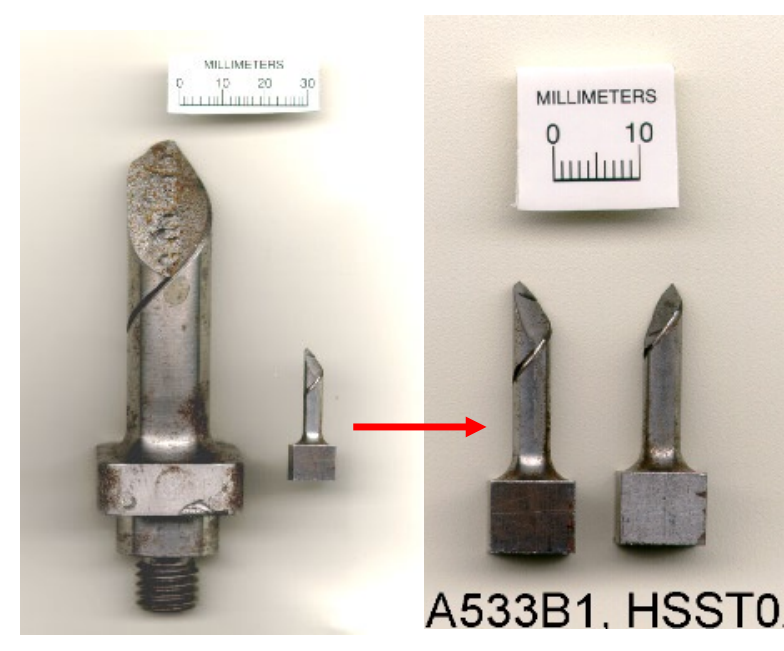

(a)

(b)

Figure 9. Fractured SNTT specimens: (a) A302B, and (b) A533B miniature sample. 
SNTT methodology is shown in Figure 10a, which shows that the principle tensile stress (opening mode) is perpendicular to the $45^{\circ}$ spiral groove line, and crack propagation is toward and perpendicular to the specimen central axis. Figure 10b illustrated the SNTT is the direct transformation of CT specimen. The CT specimen, as shown in the upper area of Figure 10b, has been widely used in existing fracture toughness test methods because the general consensus indicates it is the next-best basic configuration that nearly conforms to the strict requirements of the classical theory of fracture mechanics. Despite the simplification, the theoretical conditions (i.e., the conditions required to achieve uniformly distributed applied stress over the thickness and plane-strain condition) can never materialize as long as the free surfaces exist at both ends. The end effects will be further amplified when the thickness decreases to a thin plate, as shown in Figure 10b, where the plane stress fracture toughness is about 4-10 times larger than the intrinsic fracture toughness. Another dilemma is that an increase in specimen thickness will automatically accompany an increase in specimen length and width in order to maintain specimen rigidity under load. Miniaturization is an important goal of SNTT method. This is made possible because the $K_{\mathrm{IC}}$ values determined by the SNTT method are virtually independent of specimen size. A cursory review of the stress and strain fields in a CT specimen indicates that the key information needed for determining the $K_{\mathrm{IC}}$ values is manifested within a small region near the crack tip; therefore, the rod specimen can be miniaturized substantially without the loss of general validity (Figure 10b). The purpose of the vast volume of the material outside the critical zone in conventional samples is to poise the ideal far field of stress and to provide a means to accommodate loading devices. This redundancy is eliminated to the optimum condition in the round rod specimen; therefore, the specimen miniaturization is achievable.

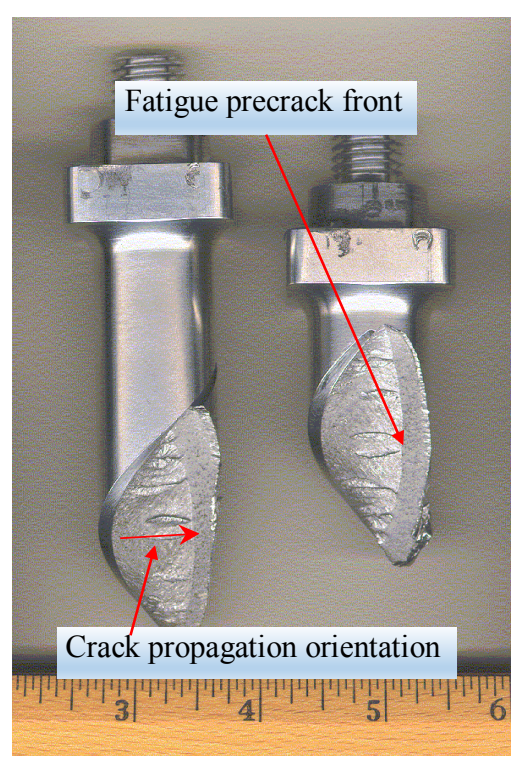

Figure 11. Fatigue precrack SNTT sample of 7475 aluminum.

Furthermore, due to the plane strain and axisymmetric constraint and the uniformity in the stress and strain fields of SNTT configuration, the crack front must propagate perpendicularly toward the specimen axis along the conoids. Post-mortem examination verified the crack propagation behavior (see Figure 11), which reveals very uniform crack front and crack propagation is perpendicular to the specimen center axis. To obtain valid results for brittle materials under conventional test conditions, a deep notch and fatigue precracking is required to develop a sharp crack front. The SNTT system with shallow notch does not require a fatigue precrack to obtain valid results for brittle samples. Such as for the SNTT test on mullite ceramic material sample, a shallow spiral V-groove with a depth of $0.5-\mathrm{mm}$ on the uniform gage section of $17-\mathrm{mm}$ diameter rod sample was sufficient for determining a valid $K_{\mathrm{IC}}$ values; the fractured mullite SNTT sample is shown in Figure 12, which shows a tensile fracture surface profile.

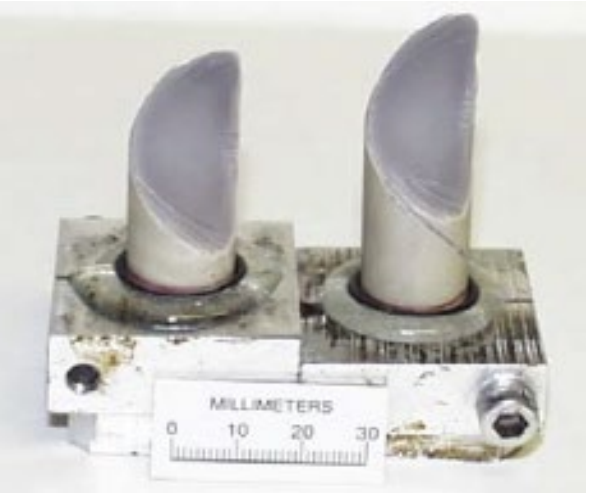

Figure 12. SNTT mullite sample. 
In typical fracture toughness tests, the direction of crack propagation is unpredictable and often deflects in zigzags or in a parabolic "thumbnail" profile, both of which yield inconsistent data. When a sample is tested in the SNTT system, the spiral notch provides a consistent location for cracking to start, and the pure torsion load ensures that the crack will advance perpendicularly toward the central axis of the test specimen. This consistent cracking behavior eliminates much of the uncertainty inherent in conventional techniques. Cracking is inherently consistent in spiral notch specimens; thus, the crack characteristics are controllable, and $K_{\text {IC }}$ values can be determined reliably.

Table 3. SNTT KIC Evaluation Comparisons.

A summary of $K_{\text {IC }}$ values for A302B steel, 7475-T7351 aluminum, mullite ceramic, MA956 alloy, and graphite are stated in Table 3 . The reader is referred to references [11-12] for details of fracture toughness evaluations.

Due to the limited experimental data obtained, no uncertainty analysis was carried out. However, the long crack front and the stringent plane strain condition should yield less uncertainty compared to conventional test methods. The characteristic features of the uniform crack fronts discerned in tested torsion samples appear to support the above statement.

\begin{tabular}{lcl}
\hline & \multicolumn{2}{c}{$K_{I C}(\mathrm{MPa} \sqrt{ } \mathrm{m})$} \\
\cline { 2 - 3 } Materials & SNTT & Method Conventional* \\
\hline A302B steel & 55.8 & $55.0 \mathrm{CT}$ \\
7475-T7351 Al & 51.3 & $51.0 \mathrm{Vendor} / \mathrm{CT}$ \\
Mullite ceramic & 2.21 & $2.203 \mathrm{P}$ \\
Concrete & 0.341 & $\mathrm{~N} / \mathrm{A}$ \\
Mortar & 1.0 & 1.0 Vendor/CT \\
Graphite &
\end{tabular}

* In TL orientation and at room temperature

\subsection{The Evolution of SNTT Compliance and Fracture Resistance for Ductile Materials}

Development of SNTT fatigue crack growth protocols in addition to a single notch-front geometry is essential for SNTT method in applying to ductile materials. The crack growth behavior of SNTT testing protocols has been effectively established using an integrated experimental, numerical and analytical approach, as illustrated in this section. The results indicate that the proposed protocol not only provides a significant advance in understanding the compliance evolution of the SNTT specimen, but also can be readily utilized to assist future developments in engineering structural materials performance reliability investigation.

Systematic studies show that the SNTT-type specimen can effectively simulate the behavior of a thick compacttension specimen with thickness equal to the spiral groove length of the SNTT sample. Finite element simulations were performed to obtain the energy release rates at different crack lengths (depth) with the corresponding torques and rotation angles. By summarizing these numerical results, the evolution of the SNTT compliance and the energy release rates were studied with respect to different crack lengths. Two nondimensional indices, the characteristic compliance and the characteristic energy release rates of SNTT, were proposed to quantify the crack growth process of SNTT. Collapse trends were observed between SNTT samples with different dimensions, as well as between samples made from both steel and aluminum. Analytical models in both broken and unbroken ligament forms were proposed to quantify the crack penetration depth based on these non-dimensional indices. The sensitivity in the broken-ligament form facilitates the experiment measurements, which could be easily adapted by industrial communities.

Figure 13(a) shows the systematic evolution of the crack growth in the SNTT sample with FEA simulations; where the diameter of the cylinder is $D$. and $a$ is the crack length. The ratio of crack length over diameter increases from 0.10 to 0.45 . The length of each model is the same during the crack growth process. Figure 13(b) shows the FEA deformation results for $a / D=0.1$ under end rotation of 0.002 radian [25]. Based on FEA simulations and experimental verification input, the evolution of the compliance function and energy release rate were developed as shown in Figure 14 and Figure 15. The details of the FEA methodology and the associated boundary conditions adopted in SNTT technology are provided in Reference 11-12. 

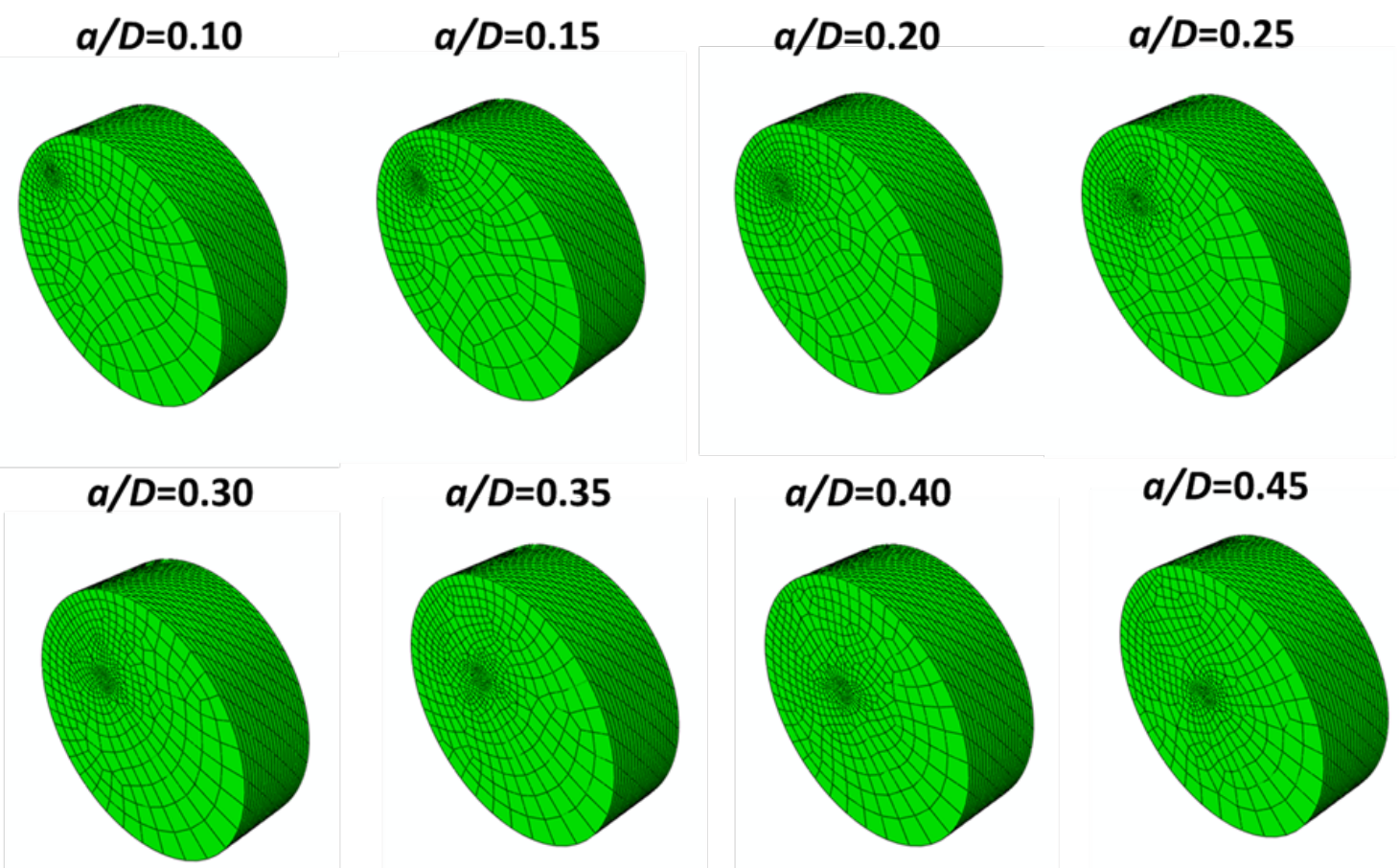

(a)
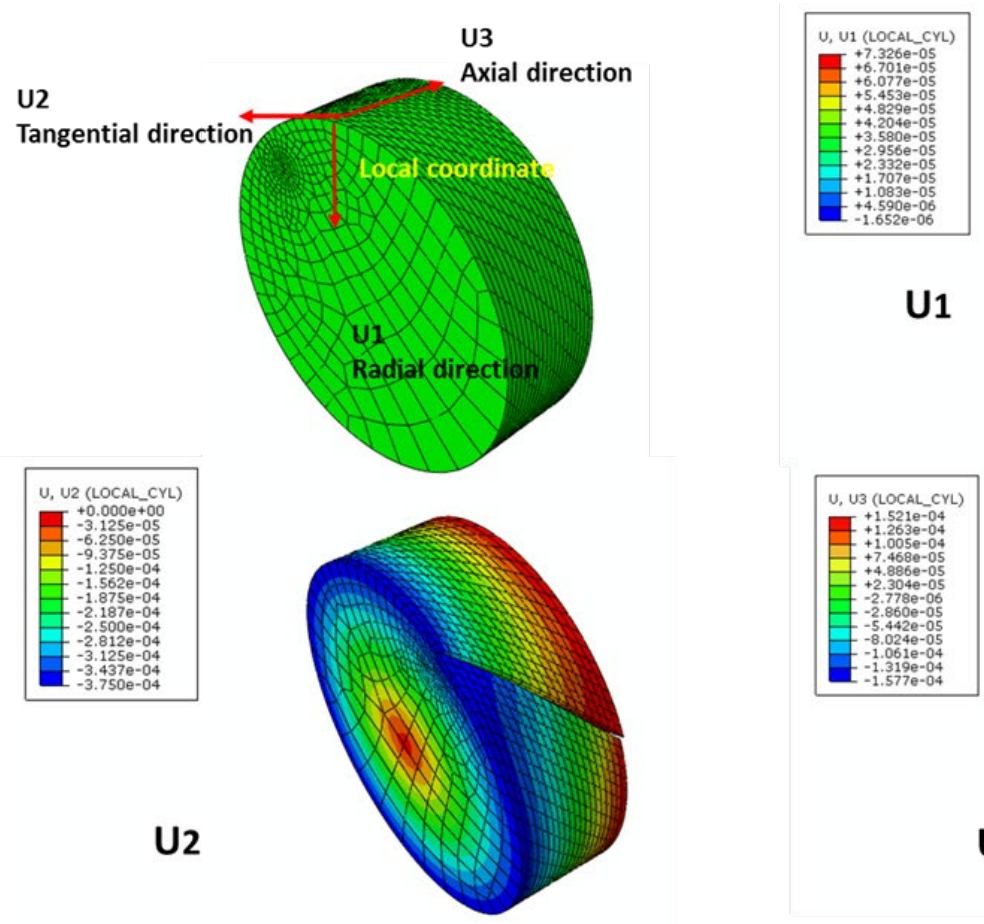

U1
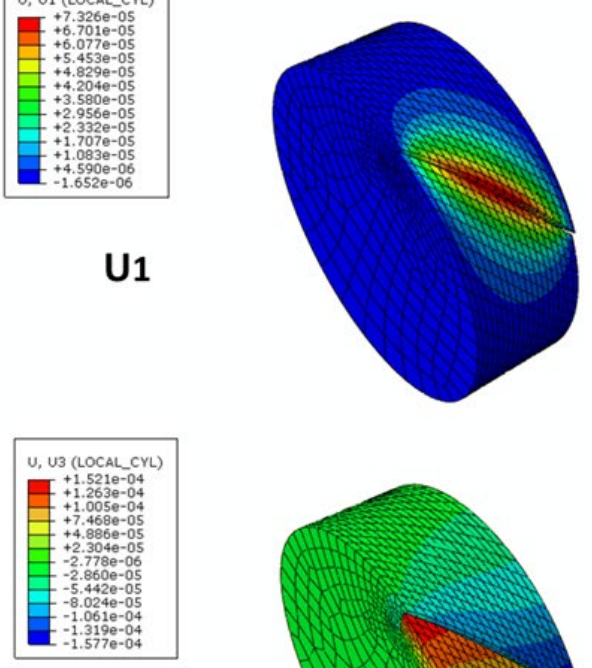

U3

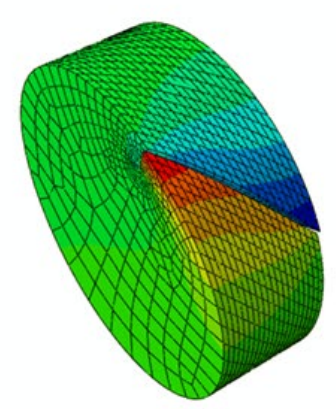

(b)

Figure 13 (a) The evolution of crack growth in the SNTT sample with FEA simulation models. (b) Single crack depth example FEA displacement results, for $a / D=0.10, D=0.375$-inch, Steel, under end rotation theta $=0.002$ with ends fixed at $U 1$ and $U 2$ orientations. 
Detailed studies show that the evolutions of compliance and fracture resistance of the SNTT sample during the crack growth process can be unified together irrespective of specimen sizes and material types. The evolutions of compliance and fracture resistance in SNTT process were formulated with simple compliance governing equations as function of the ratios of crack lengths vs. the cylindrical diameter.

The finite element simulations were established with different crack lengths for selected SNTT specimens verified by physical measurements. Where steel and aluminum SNTT specimens were selected with two diameters of 1.0 inch and 0.375 inch for analysis. The objective was to obtain the evolutions of both compliance and the fracture resistance during the crack growth process for different types of SNTT samples.

Figs. 14-15 show the evolution of crack growth in an SNTT sample with $a / D$ ratio increases from 0.10 to 0.45 . Figure 14a shows the compliance evolution of the SNTT sample with respect to different ratios of crack length over diameter. To obtain a more sensitive response of the compliance evolution, a factor was applied to account for the effect of unbroken ligament of the SNTT samples, which is graphed in Figure 14b. It shows that the compliance evolution curves are the same for specimens with different materials or sizes. $\gamma$ is the unit end rotation angle; $T$ is the applied torque; $\mu$ is the shear modulus; and $R$ is the cylinder radius.

Figure 15a shows the fracture resistance evolution of the SNTT sample with respect to crack length over diameter ratios. In order to obtain a more sensitive response of the compliance evolution, a factor also was applied to account for the effect of unbroken ligament of the SNTT samples, which is shown in Figure 15b. It was noted that fracture resistance curves are the same for specimens with different materials or sizes. $G$ is the energy release rate; $T$ is the applied torque; $\theta$ is the associated rotation angle; $A$ is the cross-section area of the cylinder.

\section{Unscaled SNTT Crack Growth Compliance Equation}

$$
\frac{\gamma}{T} \mu R^{4}=-0.6541\left(\frac{a}{D}\right)^{4}+0.5189\left(\frac{a}{D}\right)^{3}+1.7171\left(\frac{a}{D}\right)^{2}+0.2045\left(\frac{a}{D}\right)+0.6254
$$

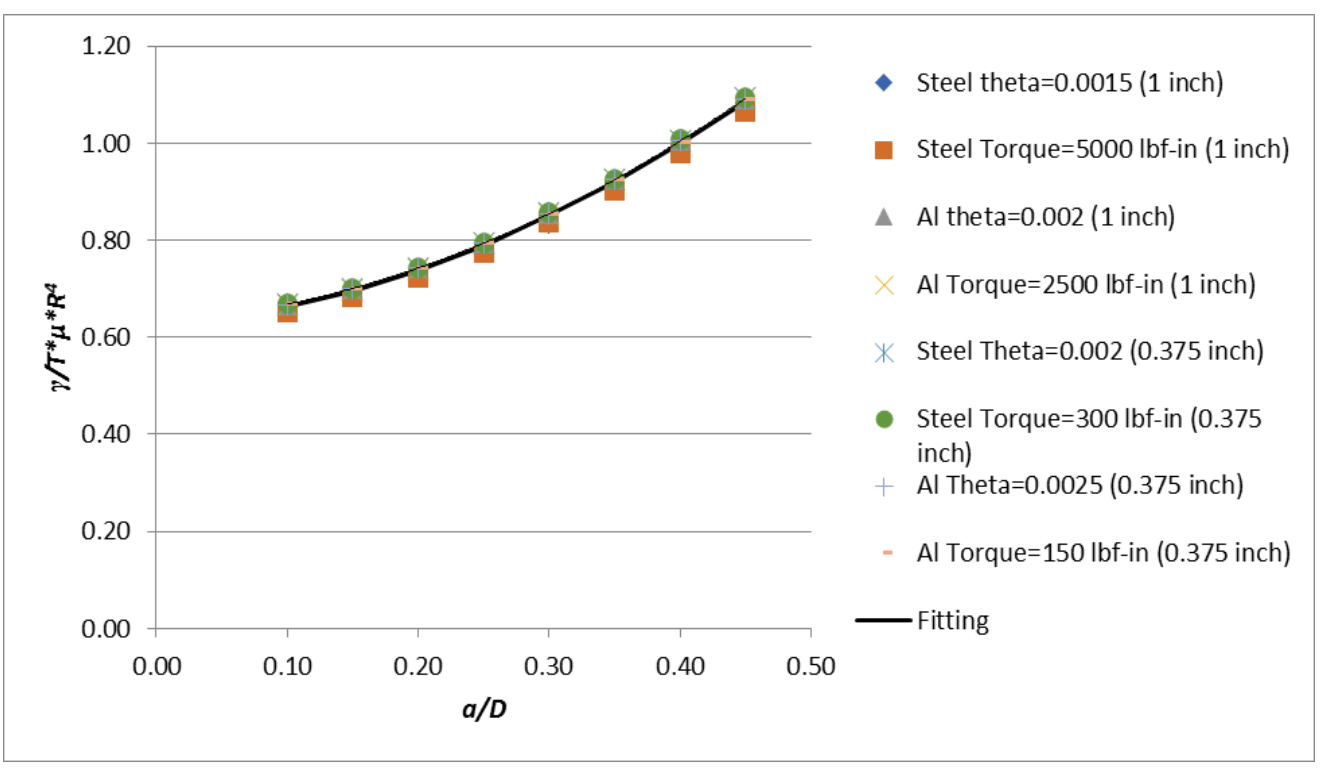

(a) 


\section{Scaled SNTT Crack Growth Compliance Equation}

$\frac{\gamma}{T} \mu R^{4}\left(1-\frac{a}{D}\right)^{4}=3.3445\left(\frac{a}{D}\right)^{4}-5.2514\left(\frac{a}{D}\right)^{3}+4.0568\left(\frac{a}{D}\right)^{2}-2.2298\left(\frac{a}{D}\right)+0.6226$

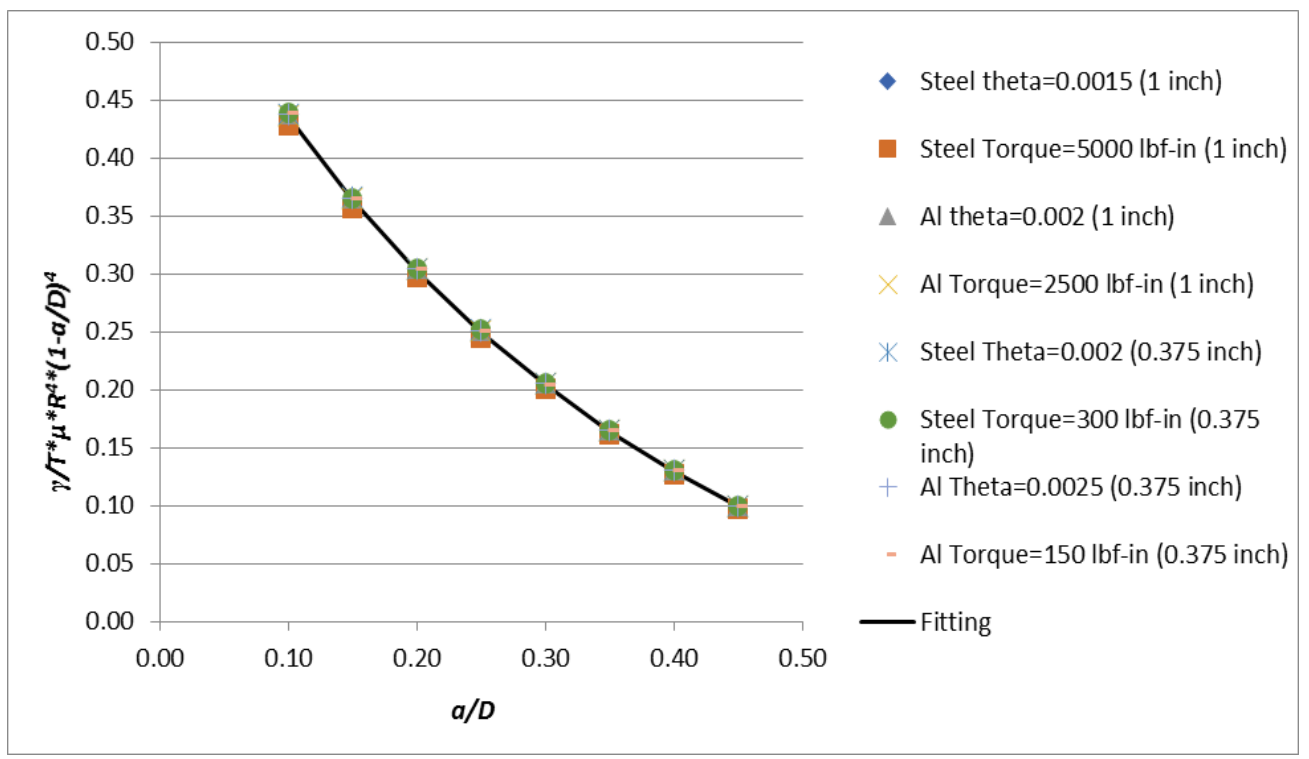

(b)

Figure 14. (a) The unscaled compliance evolution with the crack growth; (b) The scaled compliance evolution along the crack growth with unbroken ligament factor.

\section{Unscaled SNTT Energy Release Rate Evolution Equation}

$\frac{G * A}{T * \theta}=-95.543\left(\frac{a}{D}\right)^{4}+107.14\left(\frac{a}{D}\right)^{3}-52.72\left(\frac{a}{D}\right)^{2}+16.028\left(\frac{a}{D}\right)-0.2489$

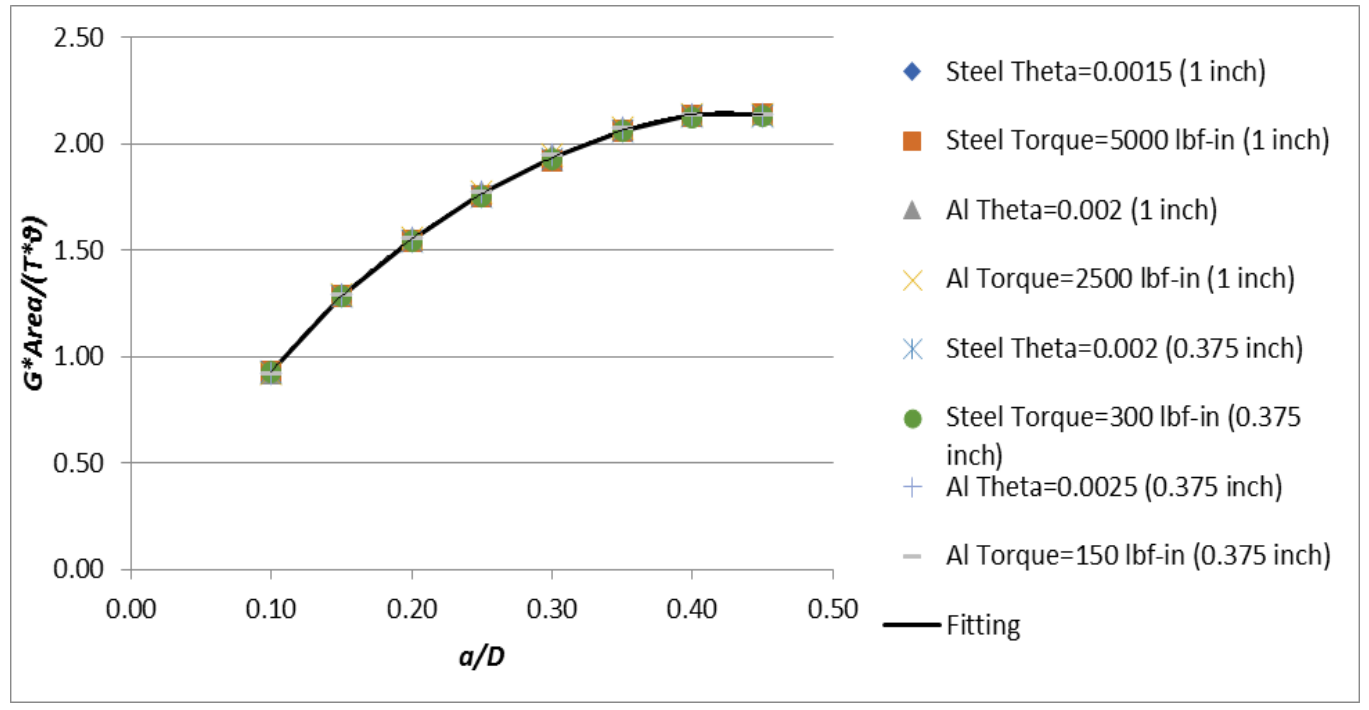

(a) 


\section{Scaled SNTT Energy Release Rate Evolution Equation}

$$
\frac{G * A}{T * \theta *\left(1-\frac{a}{D}\right)^{2}}=-154.56\left(\frac{a}{D}\right)^{4}+188.95\left(\frac{a}{D}\right)^{3}-62.398\left(\frac{a}{D}\right)^{2}+20.626\left(\frac{a}{D}\right)-0.4716
$$

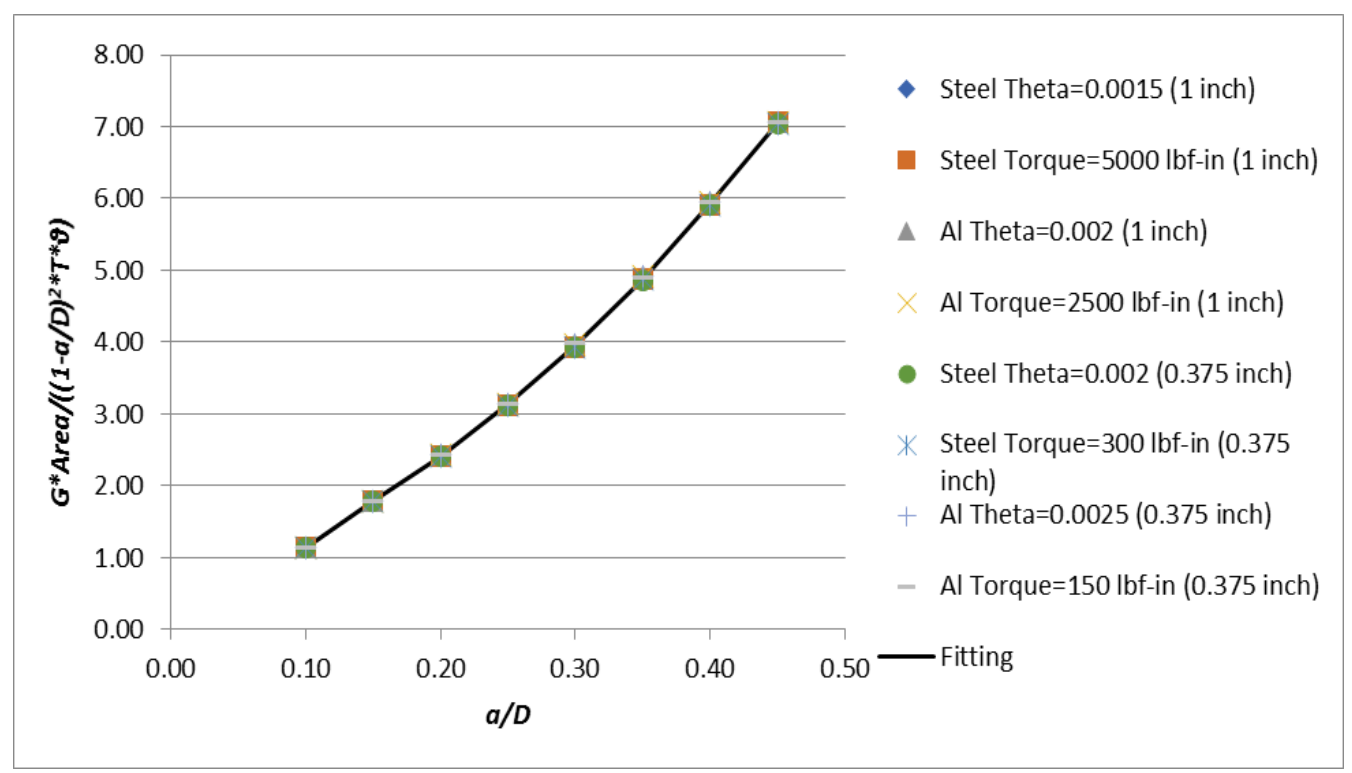

(b)

Figure 15. (a) The unscaled energy release rate evolution with the crack growth; (b) The scaled energy release rate evolution along the crack growth with unbroken ligament factor.

\subsection{Experimental Verification on the Developed SNTT Fatigue Crack Compliance Protocol}

\subsubsection{For X52 steel and X52 weld steel}

Experiment verification measurements were performed at different crack lengths during the cycle fatigue process. Fatigued specimens were cut in cross sections, and crack penetration depths were measured and compared with predictions from the developed SNTT compliance function. For the base material X52 pipe steel, a generally good agreement was observed between the crack length predictions and the postmortem experimental measurement. For the welded X52 materials, good agreements were also observed for most specimens. For some weld samples, crack deviation was observed during the cycle fatigue process. The reason for this deviation is mainly related to the flaws/impurities distribution of the welded material encountered in the fatigue pre-crack propagation path, based on postmortem examination. In order to validate the analytical models, further analysis was carried out on the rotary variable differential transformer (RVDT) measurement and finite element model predictions. The net section of the SNTT specimen was modeled with the measured crack depth. By using the torque data from the RVDT measurement, good agreement was observed between the predictions and the measurement.

X52 weld SNTT samples were fabricated from a segment of friction stir welded X52 steel pipe. The thickness of the pipe is 0.5 inch and the diameter of SNTT samples was designed as 0.375 inch accordingly. The SNTT specimen axis was parallel to the pipe cylinder axis. One complete loop of spiral groove was machined on the X52 SNTT sample. The fractured X52 baseline SNTT sample is shown in Figure 16a, the detailed fatigue precrack area is shown in Figure 16b, and the cross-section of fractured X52 weld SNTT sample is illustrated in Figure 16c. 


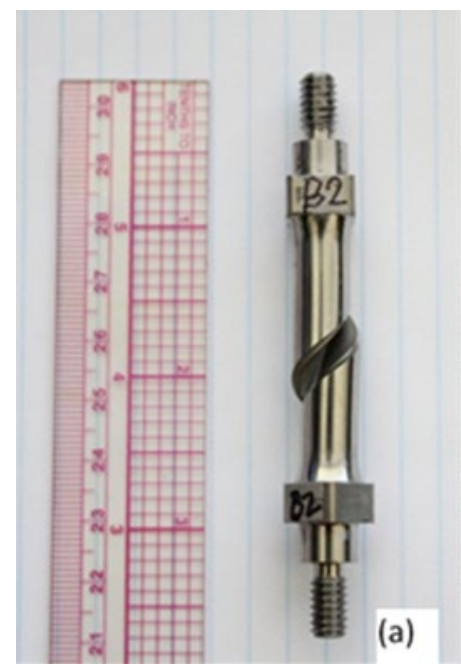

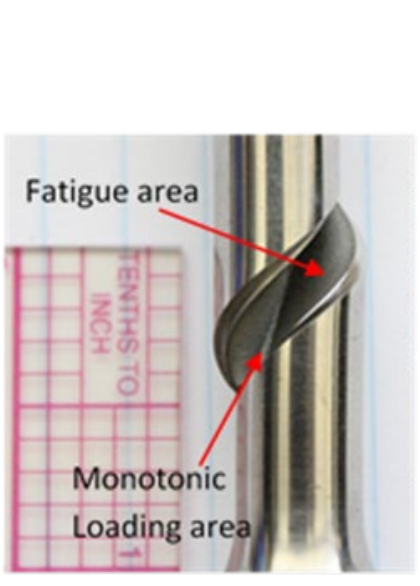

(b)

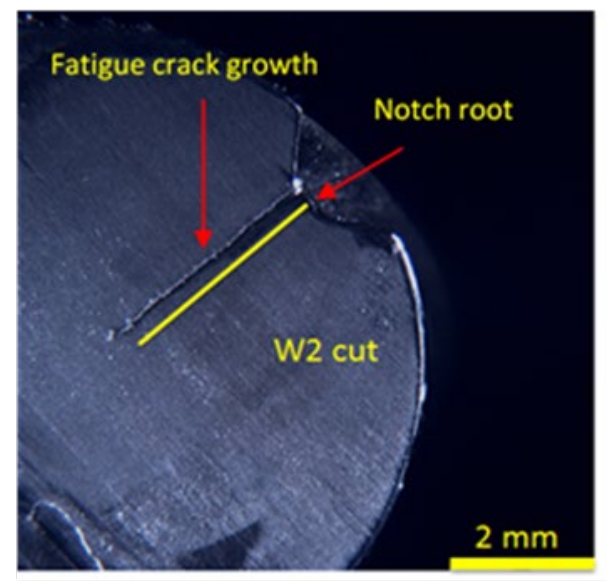

(c)

Figure 16. The failed B2 specimen of X52 baseline sample, (a) entire view; (b) enlarged view of the middle section of tested SNTT sample, (c) the fatigue pre-crack growth profile of X52 weld SNTT sample W2, where the crack growth orientation is toward the central axis of the SNTT sample.

\subsubsection{Validation using 12L14 carbon steel and SS304/308 weld steel materials}

Further validations of the SNTT compliance protocols were carried out on 12L14 carbon steel and SS302/308 weld steel, as demonstrated in Figure 17 and Figure 18 for 12L14 carbon steel and 304/308 weld steel, respectively.

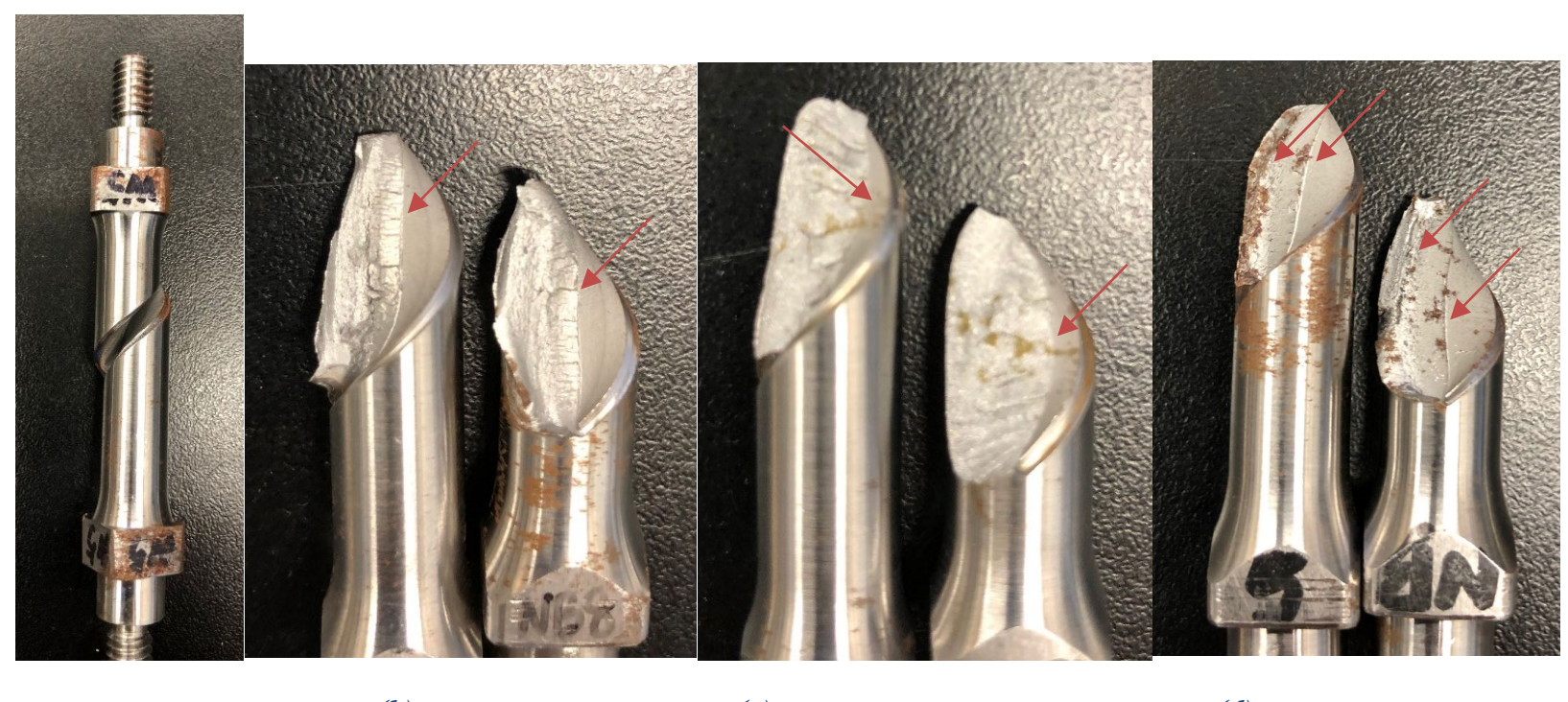

(b)

(c)

(d)

Figure 17. Fatigue-precrack fractured SNTT samples of $12 \mathrm{~L} 14$ carbon steel, at different target fatigue crack growth length, (a) crack initiation sample, (b) deep penetration fatigue pre-crack sample, (c) relative shallow pre-crack sample, (d) two consecutive fatigue pre-crack stages sample. The red arrow is pointed at the fatigue pre-crack front. 


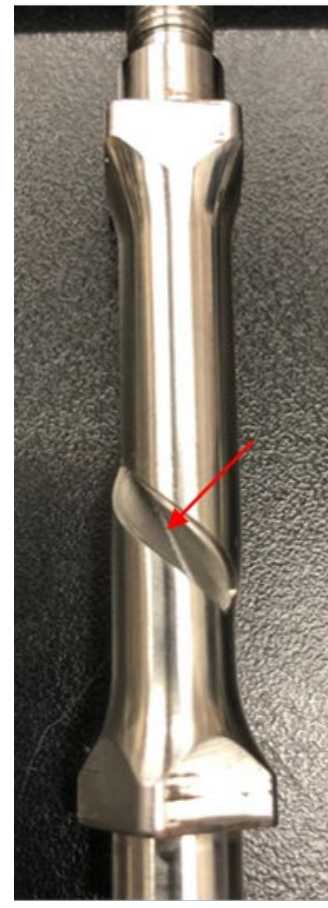

(a)

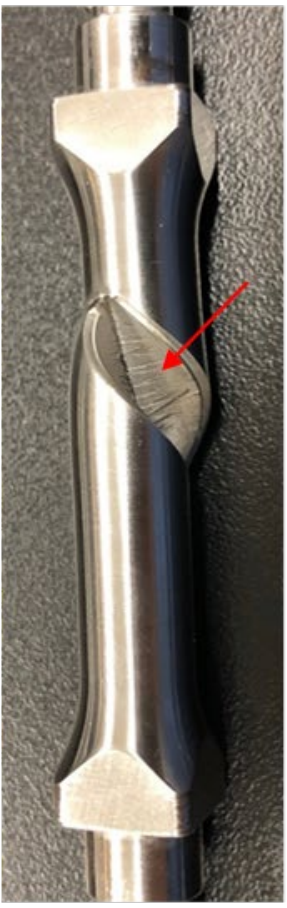

(b)

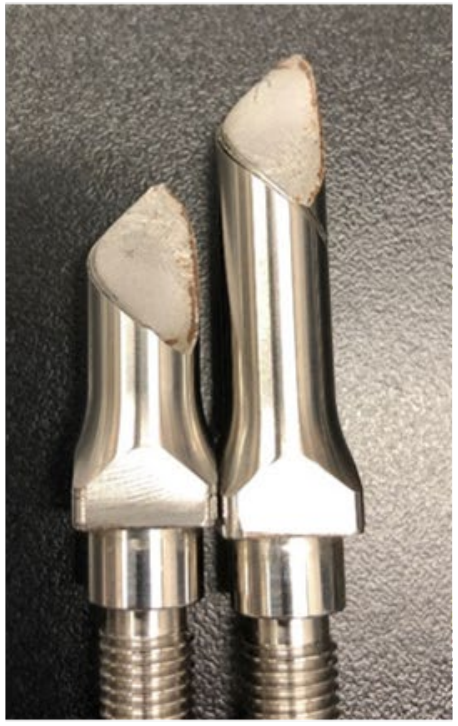

(c)

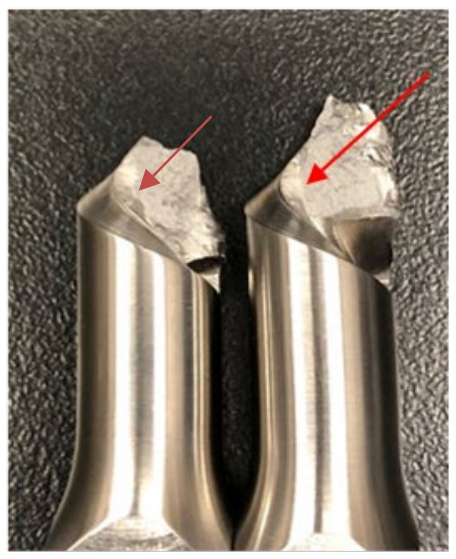

(d)

Figure 18. Fatigue-pre-crack fractured SNTT samples of 304/308 weld steel, at different target fatigue crack growth length, (a) sample with deep fatigue pre-crack initiation, (b) relatively deep penetration fatigue pre-crack sample with crack jump, (c) sample with fatigue pre-crack running through the sample cross-section, (d) fractured SNTT sample with deep spiral notch and relatively shallow fatigue pre-crack. The red arrow is pointed at the fatigue pre-crack front. 


\section{SS304/308 WELD SNTT SAMPLE PREPARATION AND BIAXIAL TESTER SET-UP}

\subsection{SNTT Specimens Designs and Configurations}

In this proposed approach, SNTT samples were fabricated from several as-received Sandia SS 304/308 weld plates. Since the thickness of the weldment is $5 / 8 \mathrm{inch}$, the diameter of the SNTT cylinder was designed to be 0.375 inch (Figure 19). The SNTT specimen axis was parallel or perpendicular to the canister cylinder axis, pending on the received weldment is axial or circumferential weld. There are several types of spiral grooves designs with different notch depths, as illustrated in Figure 20. The details of weld and HAZ SNTT specimen location machined from the weldments are illustrated in Figure 21 and Figure 22, respectively. Weld specimen only one single loop was machined in the SS304/308 weld SNTT sample, where for the deep notch HAZ samples two loops spiral groove was designed. Threads were introduced onto both ends of the SNTT samples.
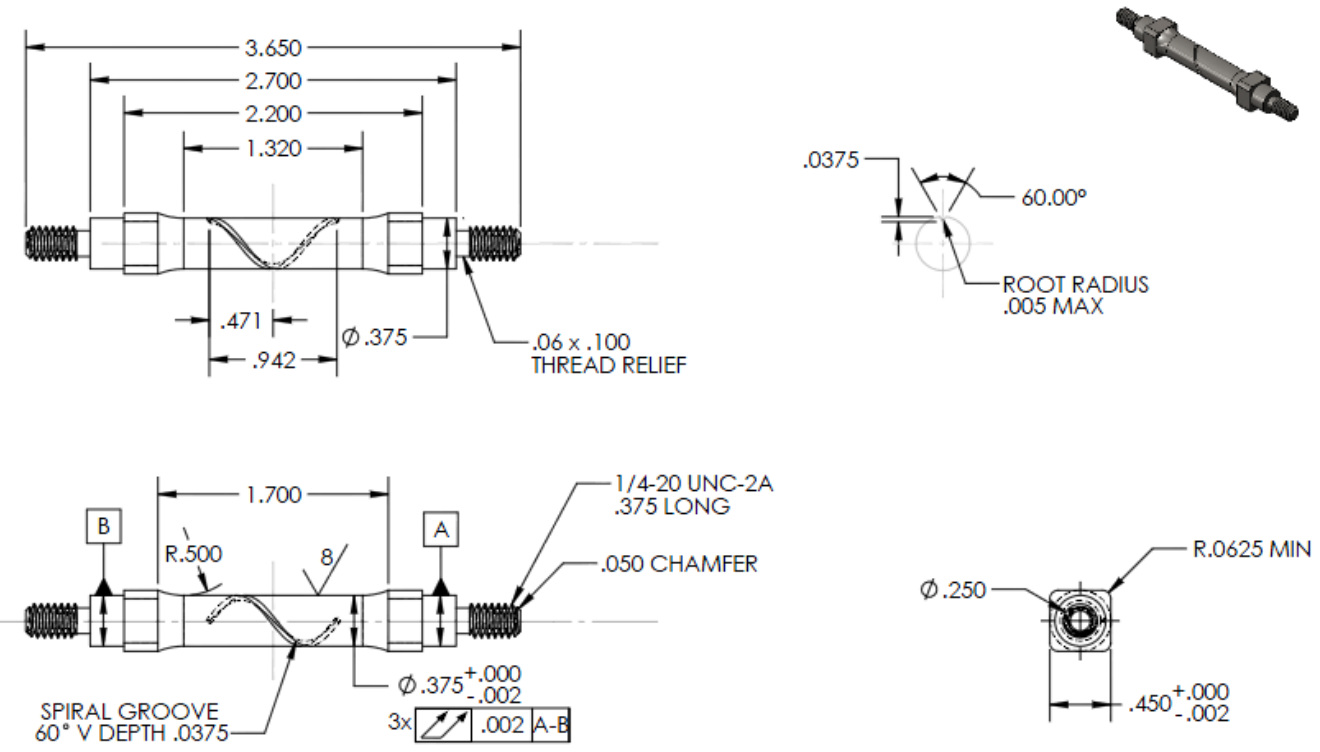

Figure 19. Geometry details of the SS304/308 weld steel SNTT specimen.

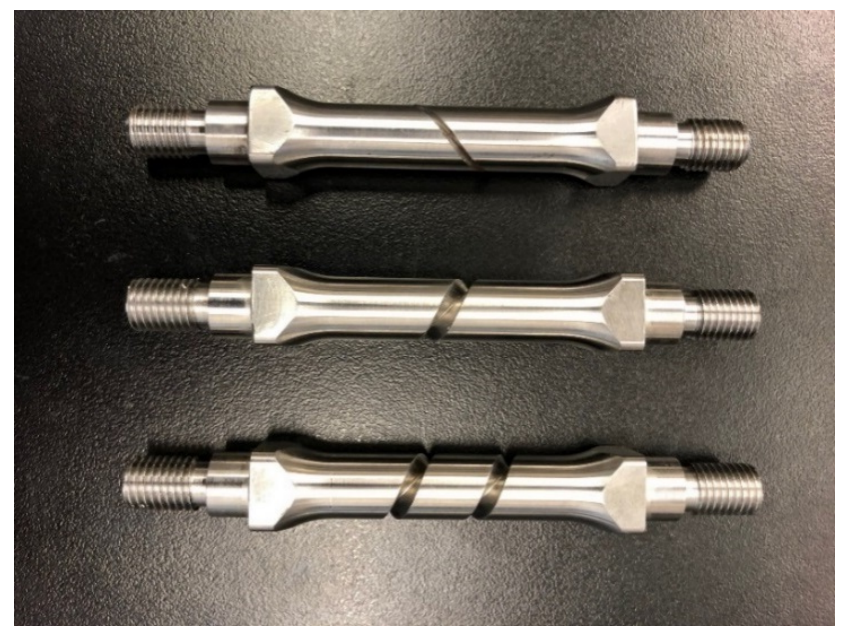

Figure 20. SNTT specimens with different spiral groove designs, (Top) single loop spiral groove with 0.0375 " notch depth, (Middle) single loop with 0.100" notch depth, (Bottom) two loops with 0.1125" notch depth. 
The weld specimen has its centerline aligned with the center of FZ; the associated gage section, and the actual dimension and location of the SNTT sample in the as-received Sandia weldment was marked with blue stripe, are shown in Figure 21. The spiral groove is located within the gage section, with the targeted notch depths.

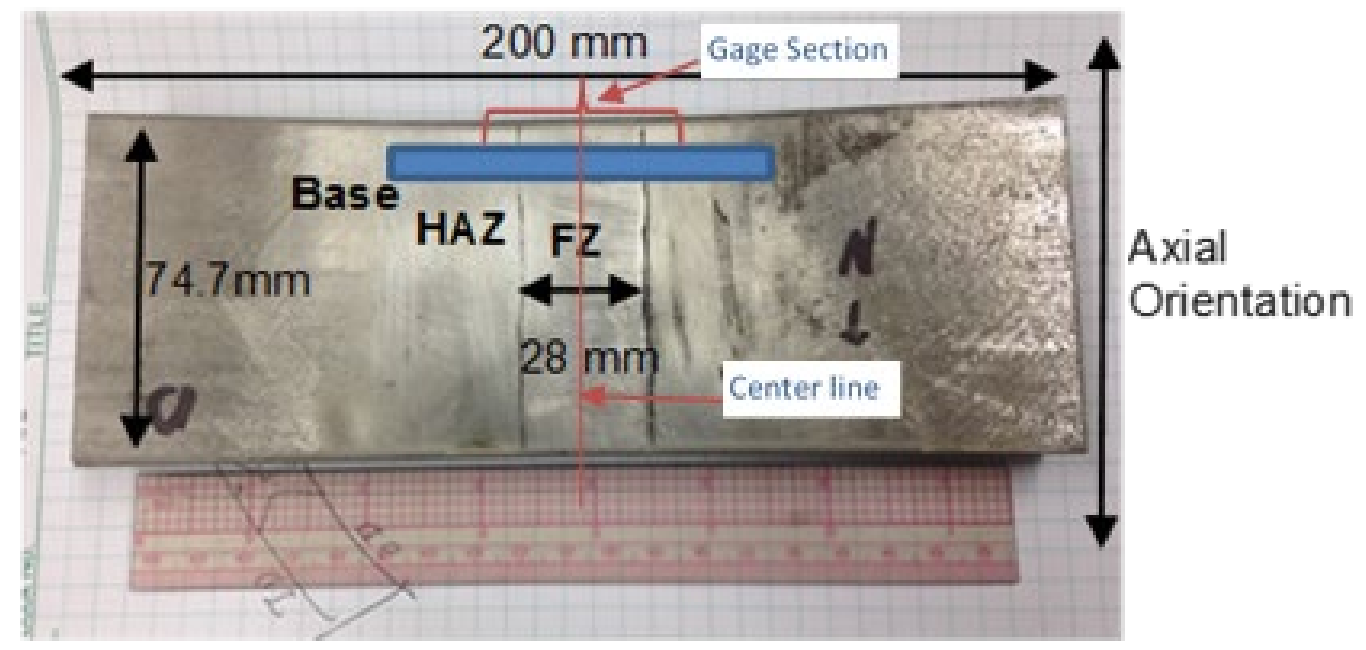

Figure 21. SNTT weld sample machining physical location in the as-received Sandia weldment.

The HAZ specimen has its centerline aligned with the edge of FZ; the associated gage section, and the actual dimension and location of the SNTT sample in the as-received Sandia weldment was marked with the blue stripe, are shown in Figure 22.

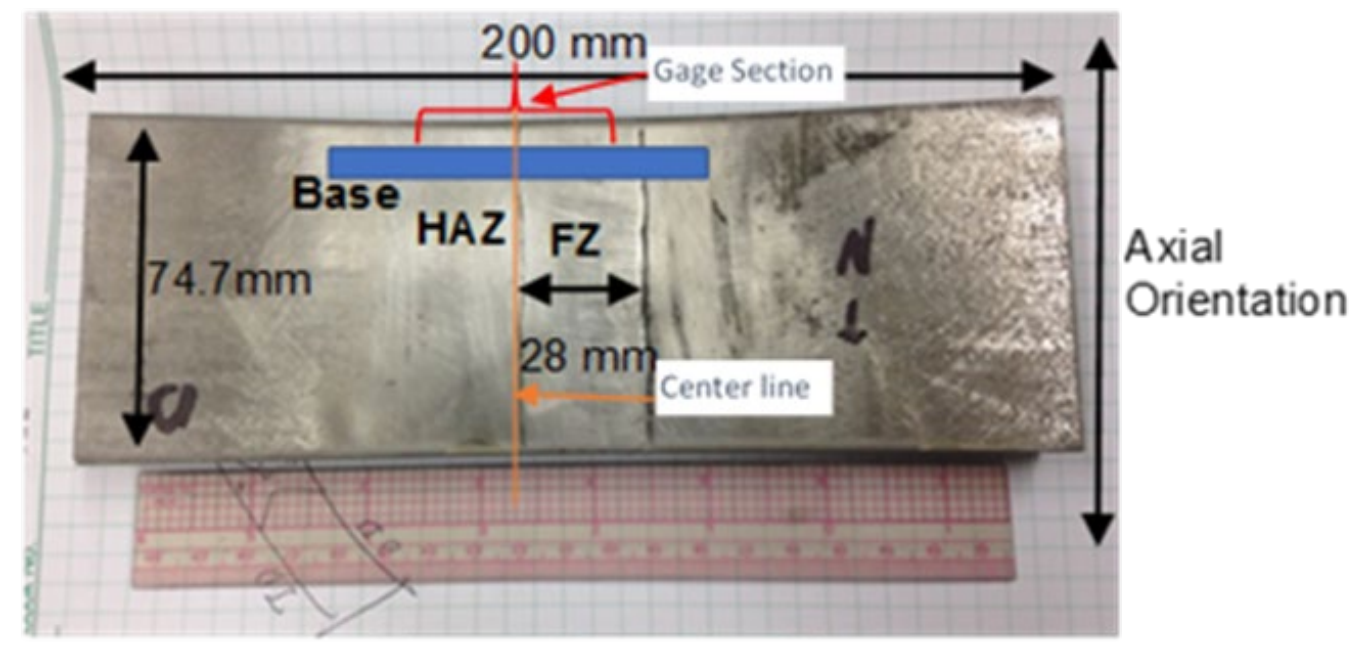

Figure 22. SNTT HAZ sample machining physical location in the as-received Sandia weldment.

\subsection{SS304/308 Weld SNTT Sample Fixture Design Configuration}

Two major concerns were addressed in the fixture and base design of SS304/308 weld SNTT samples. Because a high number of cycles were involved in the fatigue pre-crack process, threads could be coupled with bolts to stabilize the specimens. Therefore, small fixtures were designed separated to accommodate the SS304/308 weld 
SNTT samples (Figure 23), including a base was designed to connect the SNTT specimen fixture to the biaxial tester machine (Figure 24). In both the fixture and base, rotated bolt arrays were applied to secure the fastening between different components.

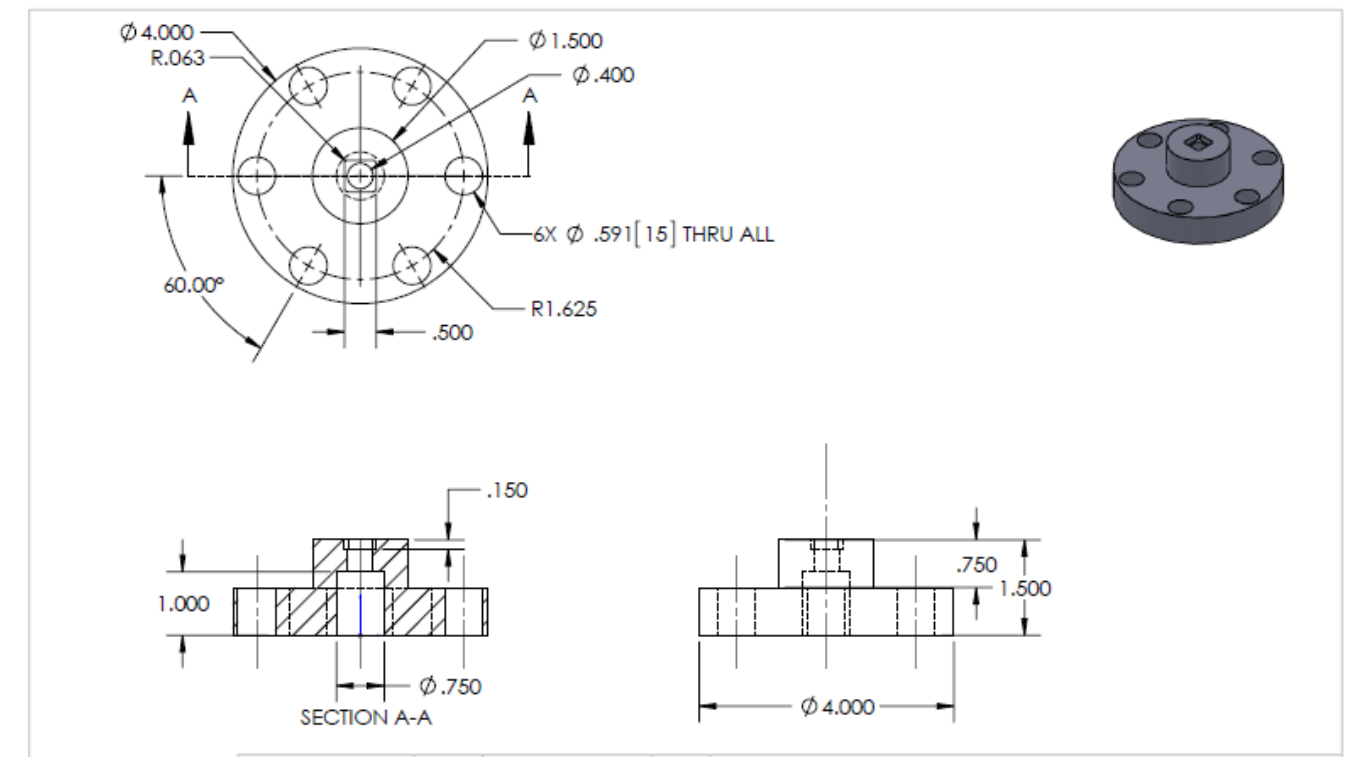

Figure 23. Schematic for fixture to adapt the 304/308 weld SNTT specimen.

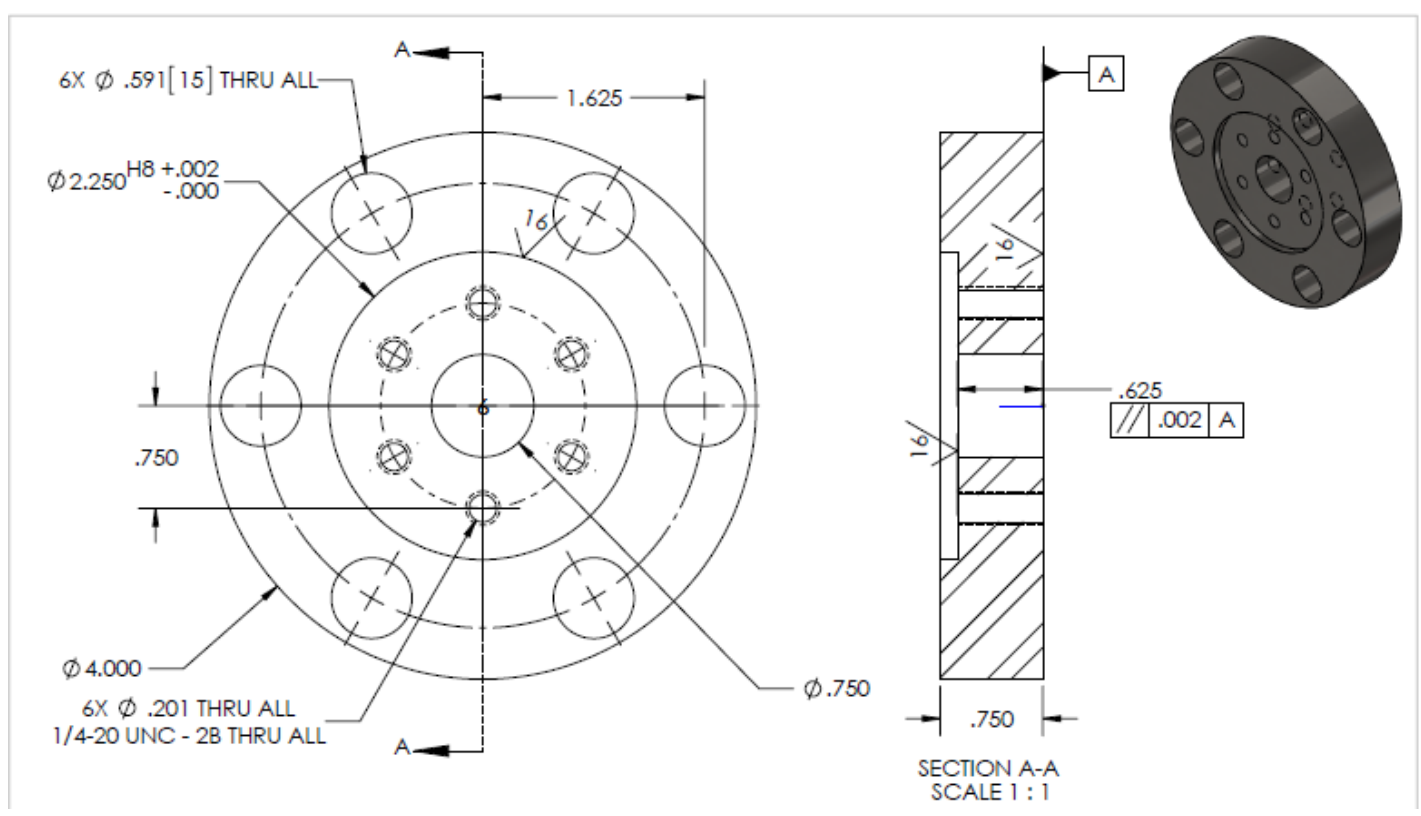

Figure 24. Schematic for base to adapt the SS304/308 weld SNTT fixture.

\subsection{SNTT Equipment Setup}

The SNTT testing of SS304/308 weld steel is primarily focused on samples machined from the as-received weld plates from Sandia mock-up canister weldment. Preliminary calculations estimate that the threshold of crack initiation in these samples with shallow notch of 0.0375 " is around $280 \mathrm{lbf}$-in. The maximum capacity of the torque load provided by the Test Resource 830 axial-torsion machine is 1,620 lbf-in. The cyclic fatigue 
frequency can reach $10 \mathrm{HZ}$ range under the targeted torque load range. These specifications ensure that cycle fatigue testing of SNTT SS304/308 weld steel specimens can be conducted, in addition to the final SNTT fatigued sample fracture testing. The detailed SNTT tester set-up is shown in Figure 25.
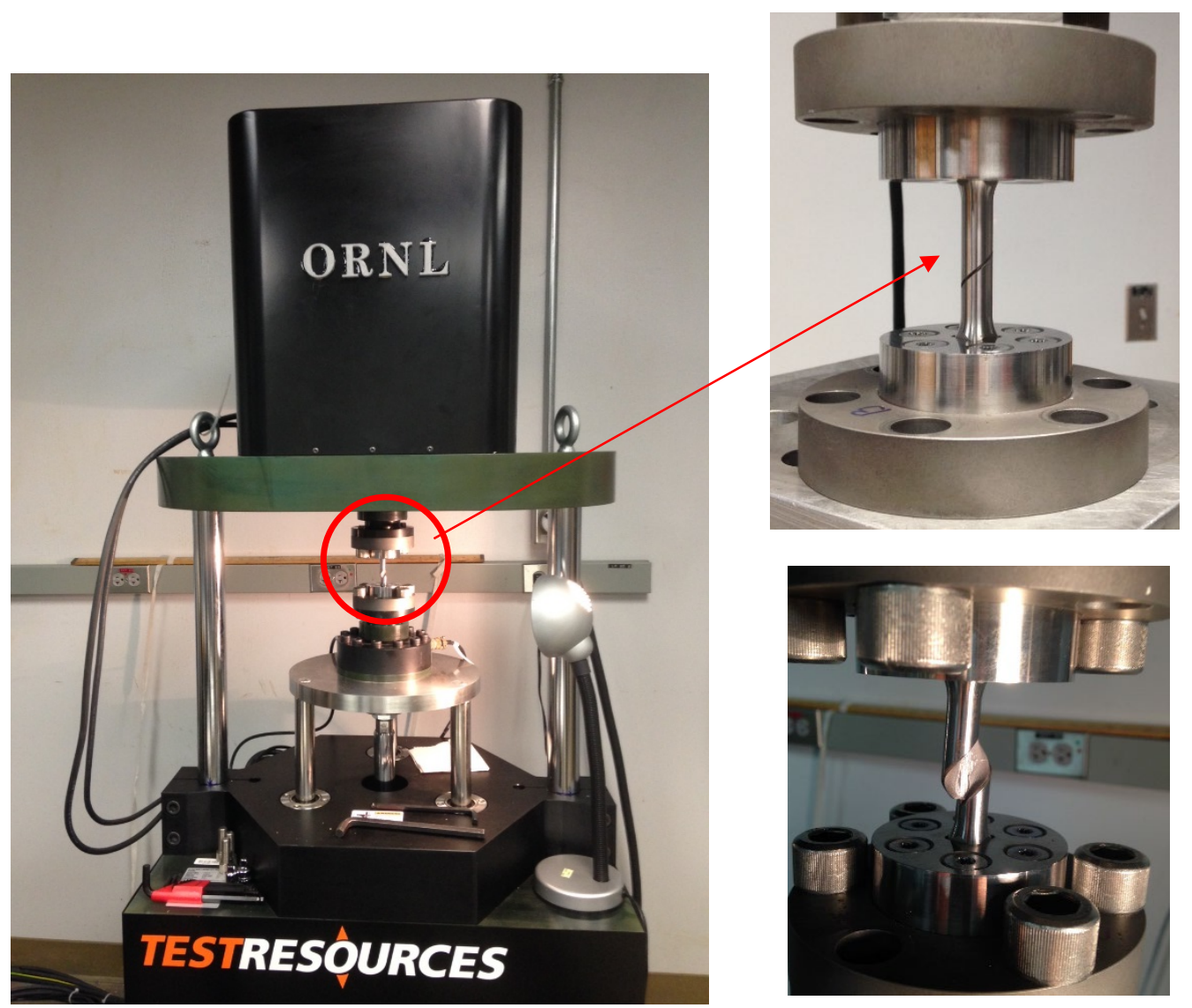

Figure 25. SNTT biaxial tester set-up, sample installation, and the final fracture tested sample. 


\section{SANDIA SS304/308 WELD FRACTURE TOUGHNESS EVALUATION}

\subsection{SNTT Testing on SS304/308 Weld Steel Material}

\subsubsection{Cycle fatigue process}

The cycle fatigue process on SS304/308 weld SNTT samples were performed through the angle control mode by a function generator built in the TestResource control system. In order to find the fatigue threshold of the SS304/308 SNTT samples, the initial maximum torque was adjusted to approximately $270 \mathrm{lbf}$-in with $5 \mathrm{HZ}$ cyclic fatigue process. This cyclic load was gradually increased to facilitate the crack growth in a reasonably time frame to reach the targeted total crack growth length ("a", notch depth plus the fatigue crack growth length); where the targeted $\mathrm{a} / \mathrm{D}$ is normally in the ranges of 0.35 to 0.45 . The crack growth during the fatigue cycles was monitored by the specimen's compliance or stiffness changes and then using the developed compliance function to estimate the crack penetration depth.

\subsubsection{Monotonic loading fracture test}

Fatigued SNTT sample was then loaded monotonically using the biaxial tester with series of loading/unloading sequences until failure; where the loading rate of $2.2 \mathrm{lbf}-\mathrm{in} /$ second and unloading rate of $17.7 \mathrm{lbf}-\mathrm{in} / \mathrm{second}$ were used. During the monotonic loading/unloading period, the axial force is maintained at nil zero condition to ensure a pure torsion loading condition. The typical experimental test results for SNTT 304/308 weld samples are shown in Figure 26 and Figure 27.
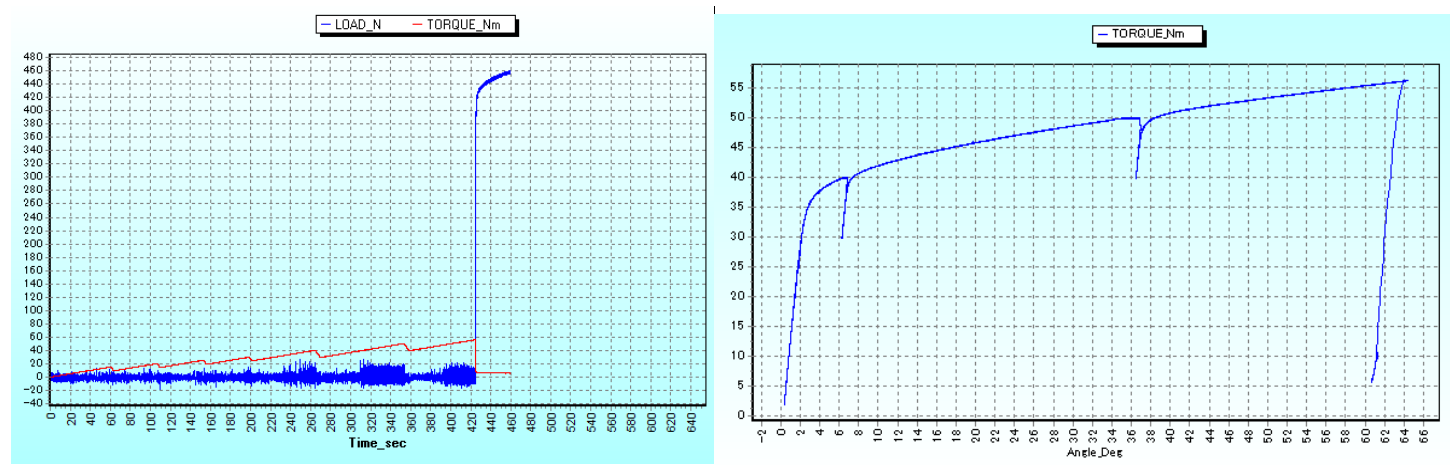

Figure 26. HAZ-1 test results, (Left) upon sudden failure a significant shock reaction was observed, (Right) The slopes of different loading and unloading sequences does not change, indicate no crack growth during the monotonic loading, the specimen undergo significant non-linear deformation before final failure, at $56 \mathrm{~N}-\mathrm{m}$ (495 Lbf-in) fracture torque.
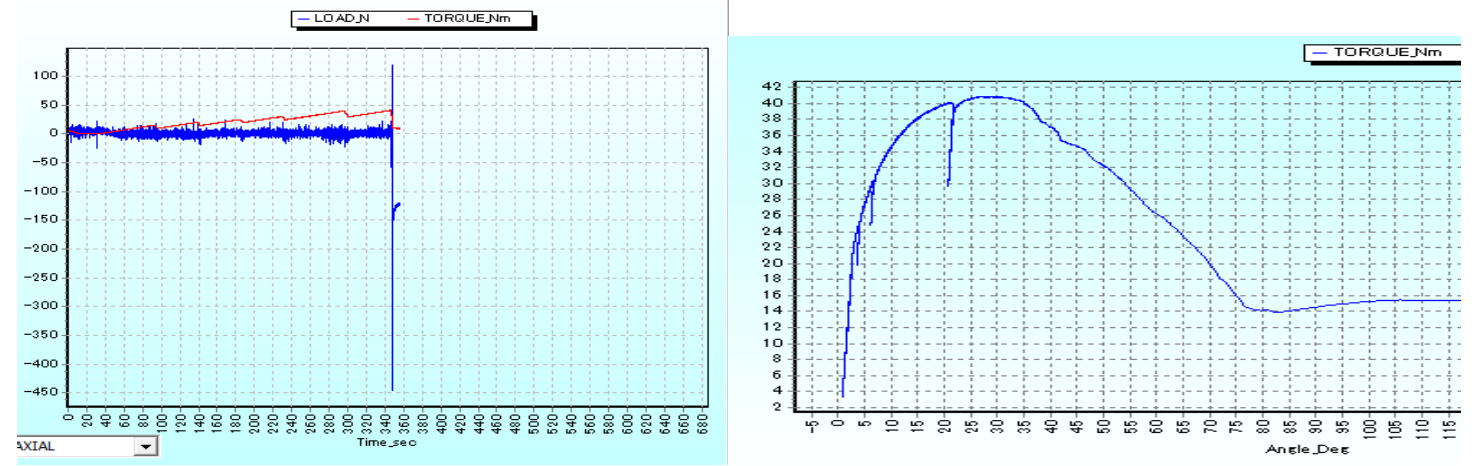

Figure 27. 2-loop Weld-4 test results, (Left) upon sudden failure a significant shock reaction was observed, (Right) The slopes of different loading and unloading sequences does not change, indicate no crack growth during the 
monotonic loading, the specimen undergo significant non-linear deformation before final failure, at $41 \mathrm{~N}-\mathrm{m}(362.8$ Lbf-in) fracture torque.

\subsubsection{Failed sample characterization}

The failed SNTT samples were characterized using an optical camera, which captured optical images of the specimen and the fractured surfaces, as shown in Figure 28 for the tested HAZ-1 SNTT sample and in Figure 29 for the tested 2-loop Weld-4 SNTT sample. Figure 28 shows that the fracture surface has smooth fatigue surface profile before final crack initiation under monotonic loading; where the HAZ-1 sample has total crack length ratio, $\mathrm{a} / \mathrm{D}$, of 0.35 .

Figure 29 shows that the 2-loop Weld-10 SNTT sample fractured into two halves during the monotonic loading. The failed surfaces from matching surfaces indicate a significant crack tip blunting occurred before the specimen final fracture. The fatigue pre-crack length is at 0.0405 and the notch depth is at 0.1125 "; the total crack length ratio, a/D, is equal to 0.40 . The fractured surface profile shows smooth pre-crack growth surface and the final fast fracture topology characteristic under monotonic loading. The fracture initiation site is near the HAZ region away from the center of FZ.

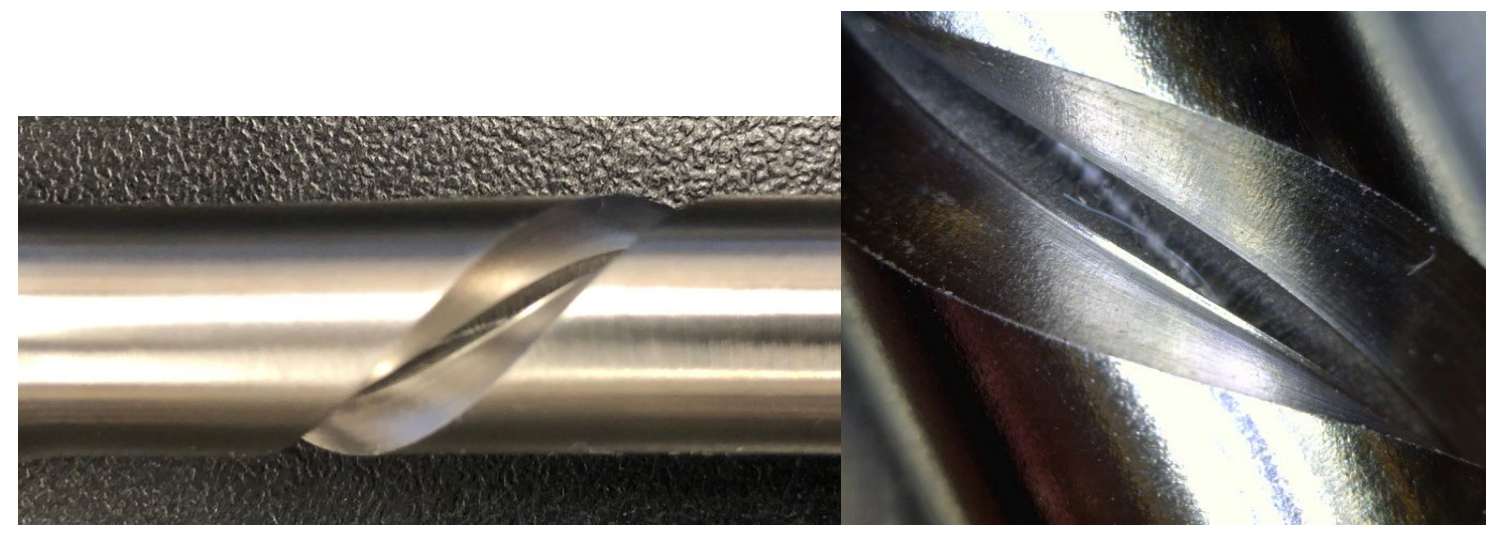

Figure 28 SNTT HAZ-1 fracture specimen and the associated fracture surface profile

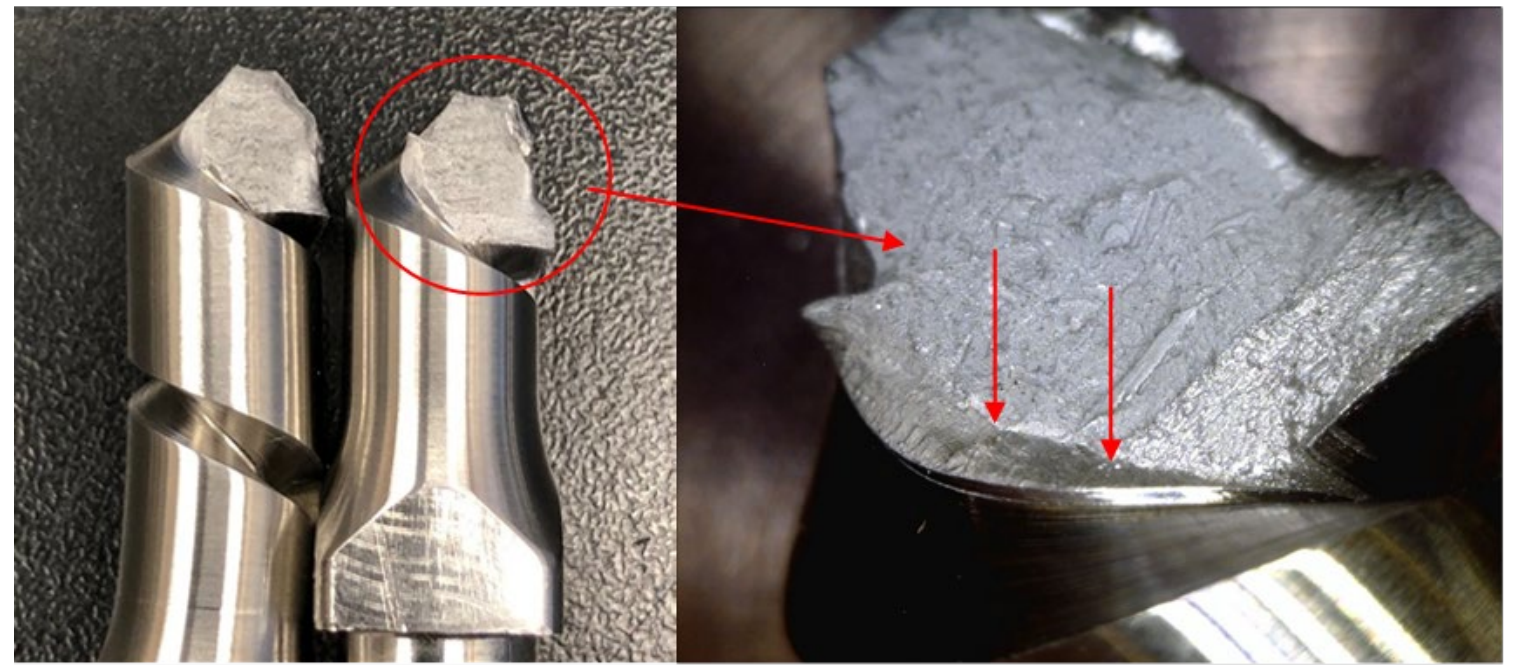

Figure 29. SNTT 2-loop Weld-10 fracture specimen and the associated fracture surface profile, the red arrows point to the fatigue pre-crack front. 


\subsubsection{SNTT 304/308 weld samples fracture test results}

The details of the SNTT 304/308 weld samples test results are illustrated in Table 4; where most weld specimens failures were initiated at HAZ region, and all the two loops weld samples were failed at or near HAZ regions, as shown in Figure 30. Table 4 shows that the fracture torques from the different tests appear to be self-consistent at the targeted a/D ratio, which indicates the good repeatability of the SNTT methodology in applying to the highly ductile SS304/308 weld materials. The large axial bending distortion observed from the fractured 2-loop deep-notch specimens is due to significant axial load reaction shock upon SNTT specimen catastrophically fractured and broken into two pieces, as shown in Figure 31.

Table 4 SNTT 304/308 weld specimens fracture test results

\begin{tabular}{|c|c|c|c|c|c|}
\hline Sample & Spiral groove & Notch depth, a0 & Total crack length, a & a/D & Fracture Torque \\
\hline ID & loop & in. & in. & \\
\hline Base-1 & 2 & 0.1125 & 0.1485 & 0.396 & 398.2 \\
\hline & & & & & \\
\hline Weld-1 & 1 & 0.0375 & 0.1313 & 0.350 & 495.6 \\
\hline Weld-2 & 1 & 0.0375 & 0.1238 & 0.330 & 486.0 \\
\hline Weld-3 & 1 & 0.0750 & 0.1313 & 0.350 & 486.7 \\
\hline Weld-4 & 1 & 0.1000 & 0.1339 & 0.357 & 496.0 \\
\hline Weld-5 & 1 & 0.1000 & 0.1665 & 0.440 & 340.7 \\
\hline Weld-6 & 1 & 0.1000 & 0.1538 & 0.410 & 367.2 \\
\hline Weld-7 & 2 & 0.1125 & 0.1905 & 0.508 & 309.7 \\
\hline Weld-8 & 2 & 0.1125 & 0.1560 & 0.416 & 349.9 \\
\hline Weld-9 & 2 & 0.1125 & 0.1575 & 0.420 & 338.1 \\
\hline Weld-10 & 2 & 0.1125 & 0.1530 & 0.408 & 362.8 \\
\hline & & & & & 495.6 \\
\hline HAZ-1 & 1 & 0.0750 & 0.1313 & 0.350 & 495.6 \\
\hline HAZ-2 & 1 & 0.0750 & 0.1313 & 0.350 & 490.0 \\
\hline HAZ-3 & 1 & 0.0750 & 0.1350 & 0.360 & 495.0 \\
\hline HAZ-4 & 1 & 0.0375 & 0.1275 & 0.340 & \\
\hline
\end{tabular}

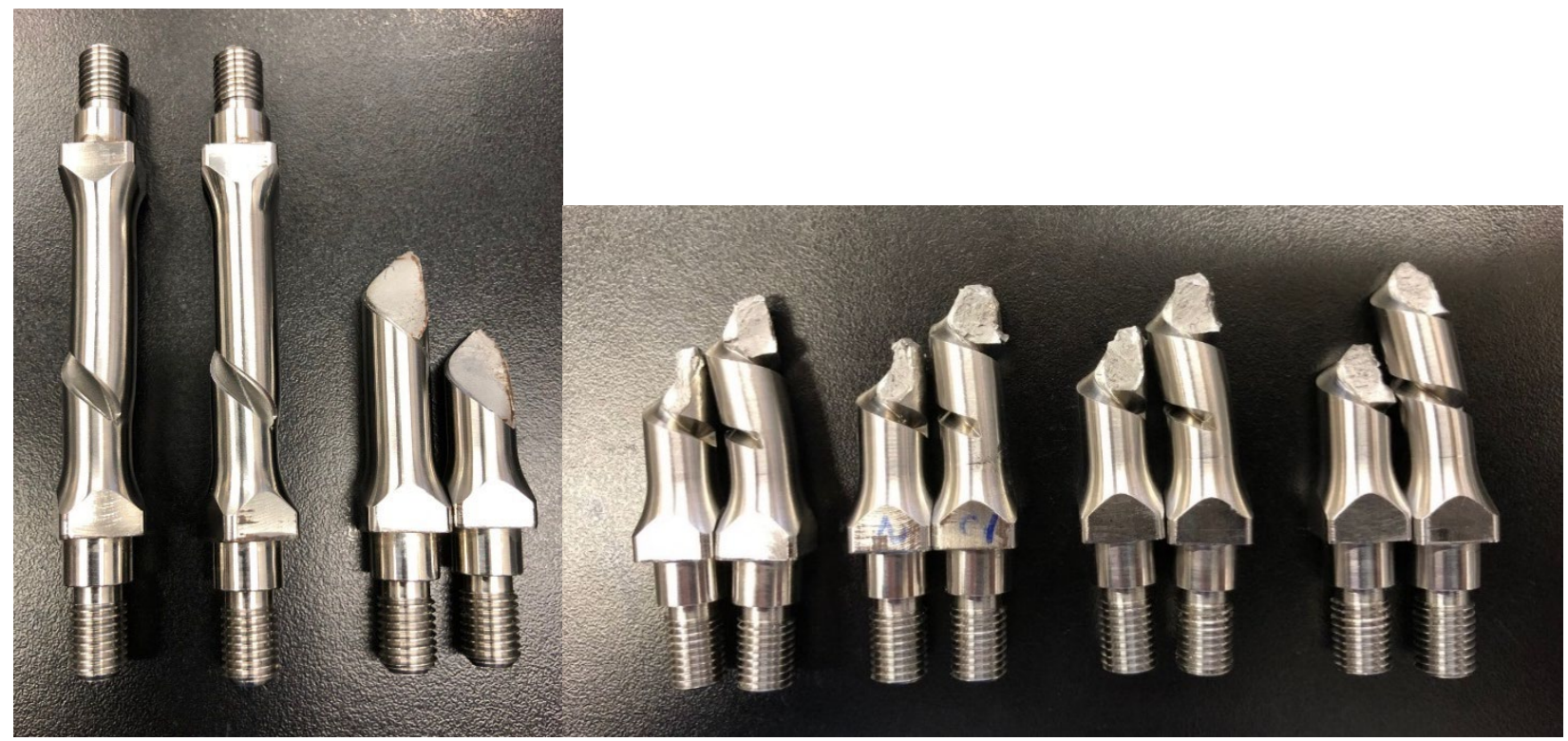

Figure 30. (Left) Most SNTT weld 1-loop shallow-notch specimens' failures are initiated at HAZ regions, (Right) All the weld 2-loop deep-notch specimens are failed at $H A Z$ regions. 


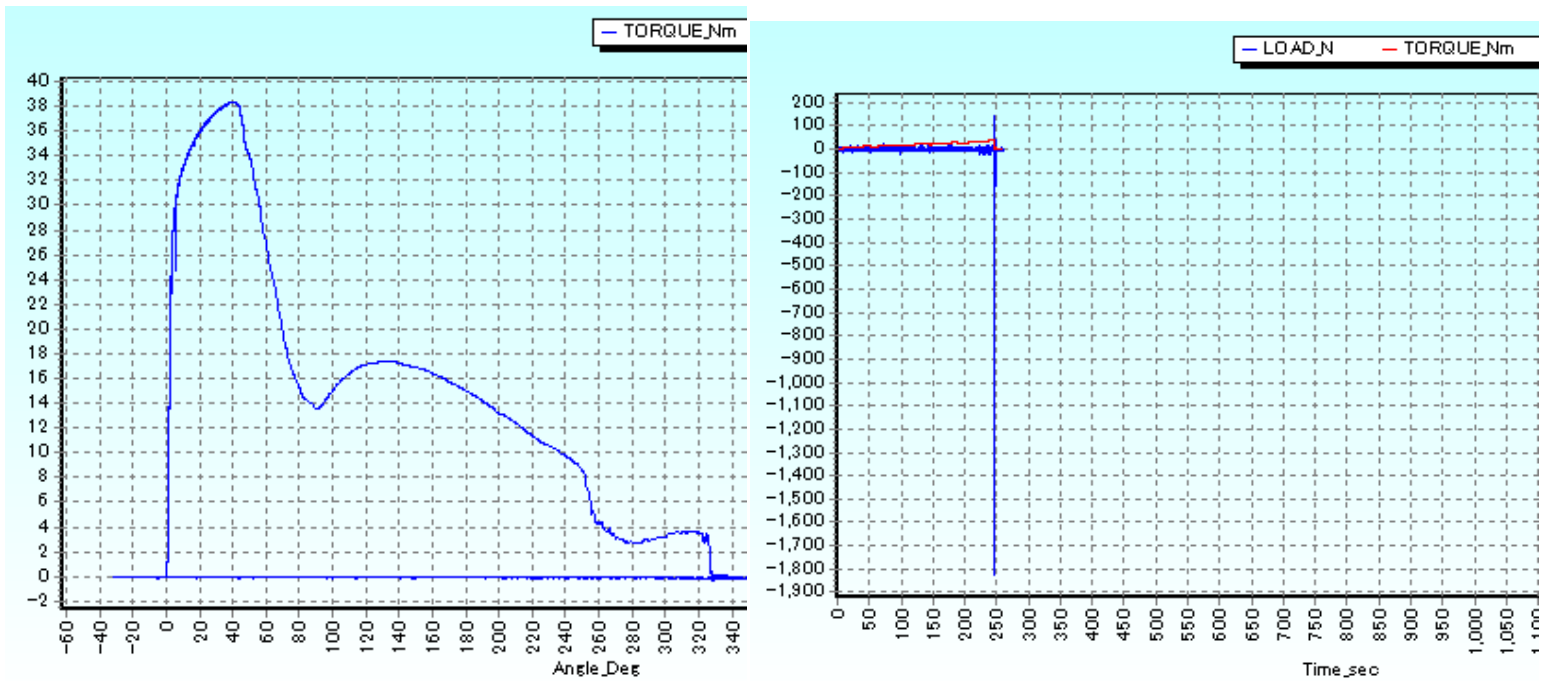

Figure 31. SNTT Weld-9 specimen fracture test results, (Left) Torque vs. angle data, and (Right) Upon failure significant axial load shock was observed, reaching magnitude of $\sim 1800 \mathrm{~N}$. 


\subsection{Fracture Toughness Evaluation on the Tested SNTT HAZ and Weld Samples}

\subsubsection{SNTT finite element modeling methodology for ductile materials}

The methodology used for developing finite element model (FEM) and the typical FEM analyses results are illustrated in Figure 32. The FEM designed for the ductile material SNTT fatigue pre-crack sample characterization was used for demonstration. Due to high ductility of the 304/308 weld material, the singular wedge element with quarter-node elements around crack tip was relaxed back to normal wedge element with middle-node elements. The typical FEM analyses results are also shown in Figure 32, where the tri-axial tensile stress profiles and the butterfly plastic process zone indicate a high geometry constraint condition exists in the proposed SNTT fracture toughness testing protocol.
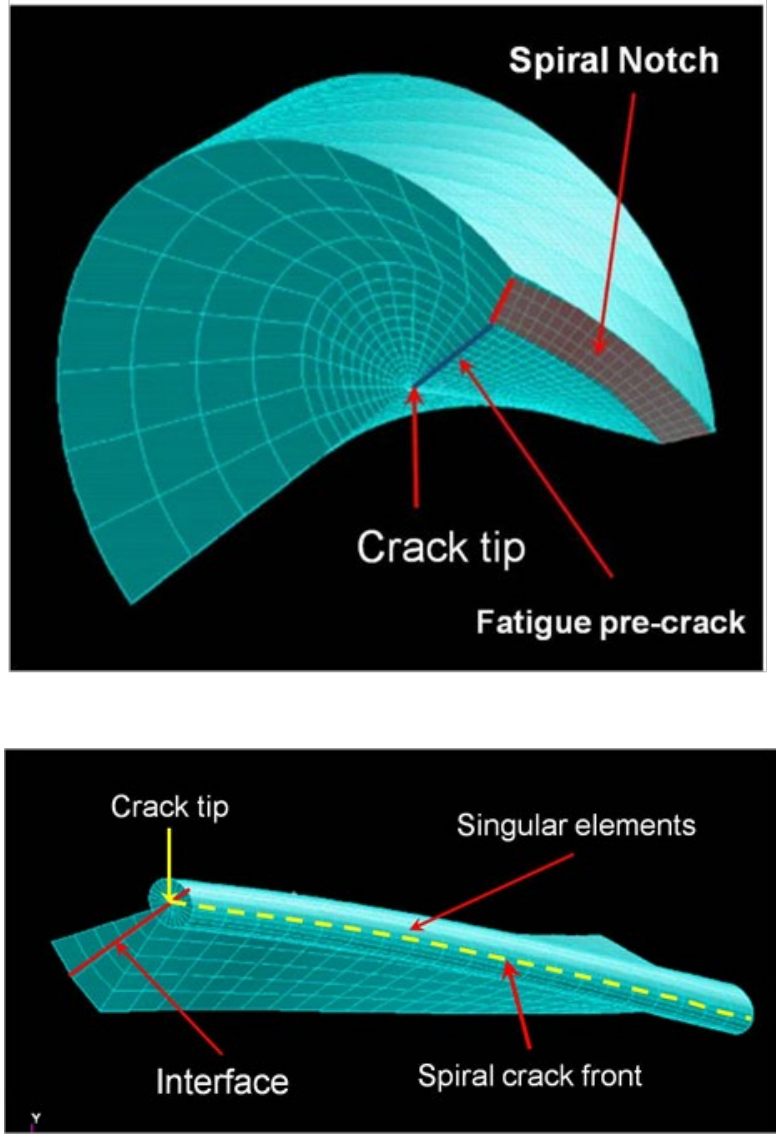

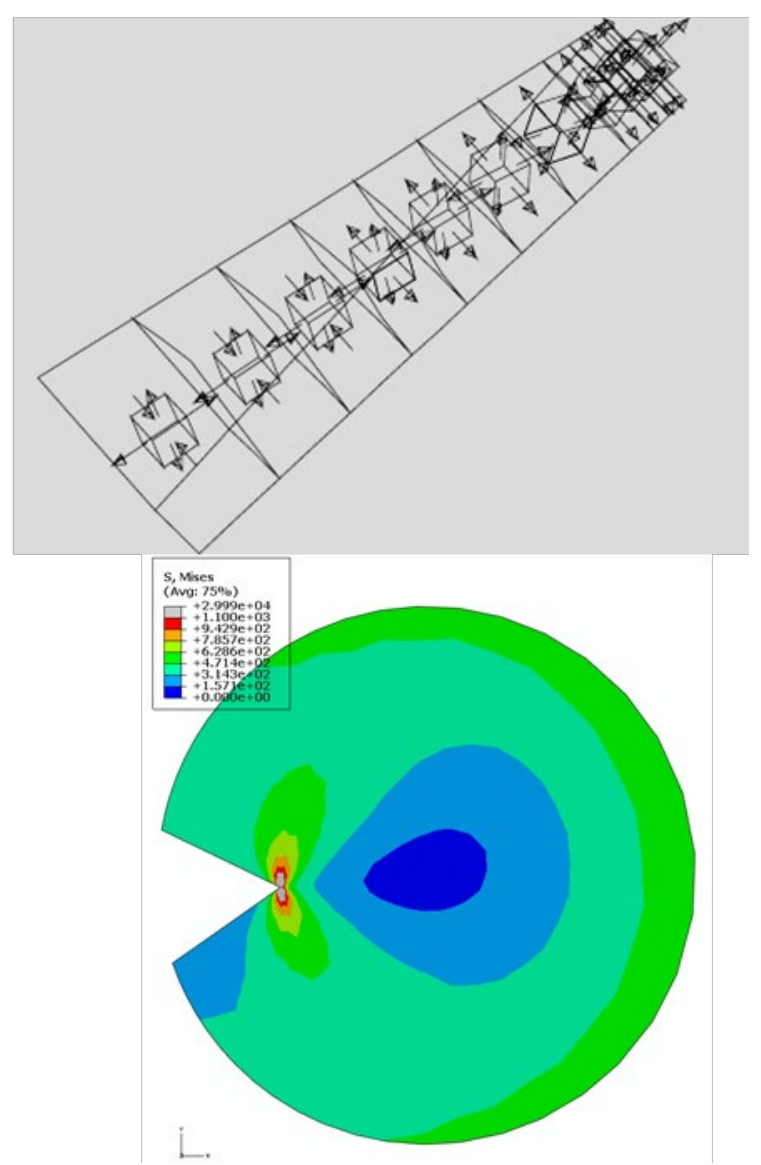

Figure 32. (Left) Typical finite element models used for ductile material fracture toughness characterization, due to high ductility of the 304/308 weld material, the singular wedge element with quarter-node element was relaxed back to normal wedge element with middle-node element; (Right) Typical FEM analyses results that indicate tri-axial tensile stress at near crack tip and butterfly plastic process zone around the crack tip, which indicate a high geometry constraint toughness testing configuration.

\subsubsection{FEM analyses and energy release rate evaluation for SNTT HAZ-1 specimen test results}

The finite element model used for evaluating the apparent energy release rate, or $\mathrm{J}_{\mathrm{Q}}$, is shown in Figure 33, where 105,698 nodes and 25,080 3-D solid elements were used to model SNTT HAZ-1 specimen with a crack length of $0.1313 \mathrm{inch}$. The fractur torque is at $495.6 \mathrm{lbf}-\mathrm{in}$. The deformed FEM model upon failure and the estimated von Miss stress contours are shown in Figure 34. The Abaqus J-contour integral routine with 9- 
contours option was used to determine the $\mathrm{J}$ value. Near middle layer's J-contour data were used to estimate $\mathrm{J}_{\mathrm{Q}}$ for SNTT 304/308 weld HAZ-1 specimen upon final fracture; which results in $\mathrm{J}_{\mathrm{Q}}=720 \mathrm{lb} / \mathrm{in}\left(126.1 \mathrm{KJ} / \mathrm{m}^{2}\right)$.

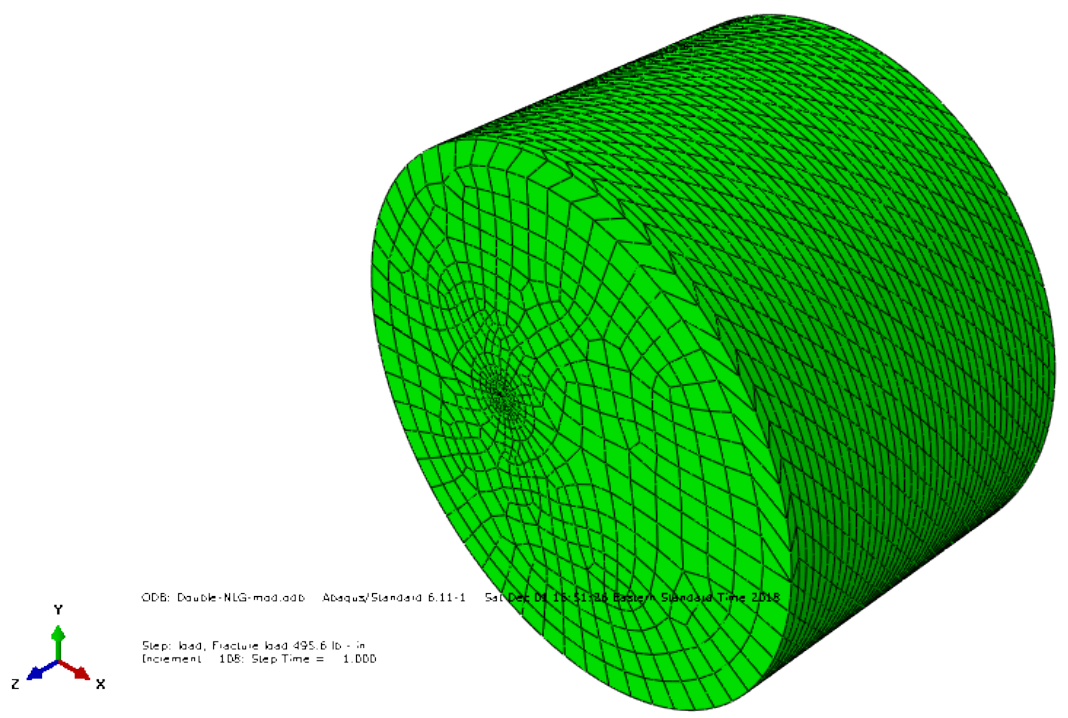

Figure 33. Finite element model for SNTT HAZ-1 specimen test simulation.
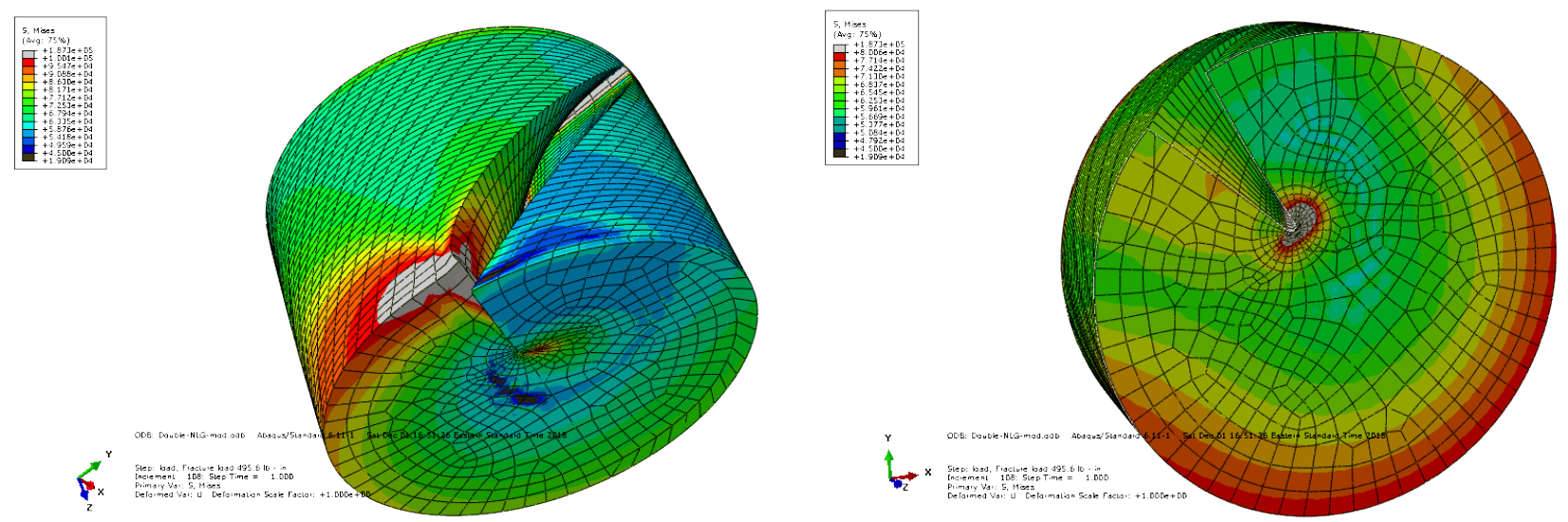

Figure 34. (Left) Full model FEM deformation and von-Miss stress profile, (Right) Deformation and von Miss stress profiles at near middle layer of finite element model.

\subsubsection{FEM analyses and energy release rate evaluation for SNTT Weld-10 specimen test results}

The finite element model used for evaluating the apparent energy release rate or $\mathrm{J}_{\mathrm{Q}}$ is shown in Figure 35, where 89,603 nodes and 21,280 3-D solid reduced-integration elements were used to model SNTT Weld-10 specimen with a crack length of 0.153 inch. The fractur torque is at $362.8 \mathrm{lbf}$-in. The deformed FEM model upon failure and the estimated von Miss stress contours are shown in Figure 36. The Abaqus J-contour integral routine with 9-contours option was used to determine $\mathrm{J}$ value. Near middle layer's $J$-contour data were used to estimate $\mathrm{J}_{\mathrm{Q}}$ for SNTT 304/308 Weld-10 specimen upon final fracture; which results in $\mathrm{J}_{\mathrm{Q}}=850 \mathrm{lb} / \mathrm{in}\left(148.8 \mathrm{KJ} / \mathrm{m}^{2}\right)$. 


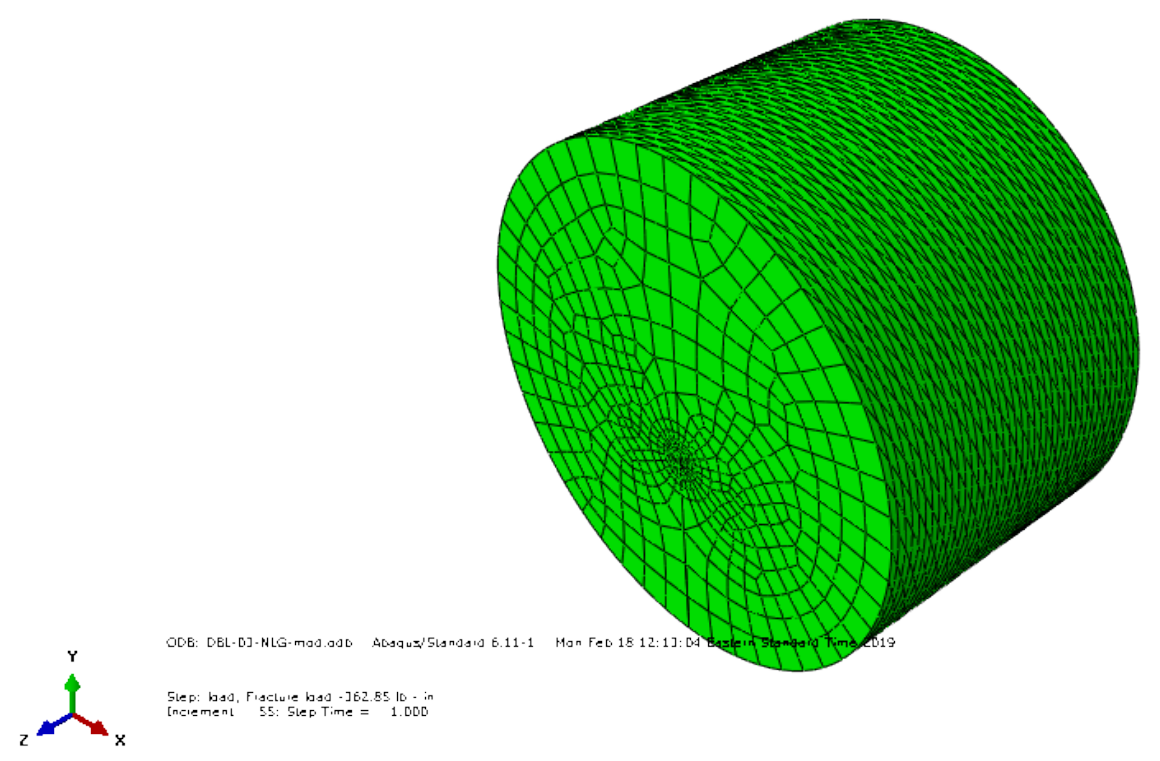

Figure 35. Finite element model for SNTT Weld-10 specimen test simulation.
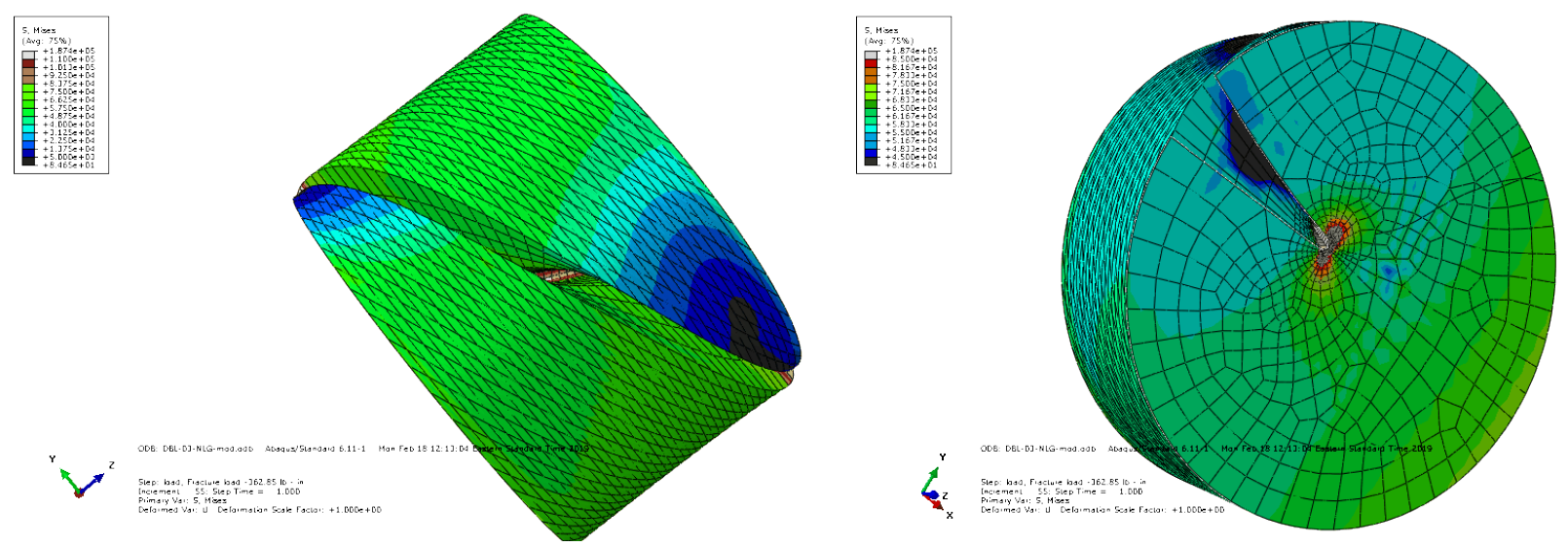

Figure 36. (Left) Full model FEM deformation and von-Miss stress profile, (Right) Deformation and von Miss stress profiles at near middle layer of finite element model.

\subsubsection{FEM analyses and energy release rate evaluation for SNTT Base-1 specimen test results}

The finite element model used for evaluating the apparent energy release rate, or $\mathrm{J}_{\mathrm{Q}}$, is shown in Figure 37 , where 89,603 nodes and 21,280 3-D solid reduced-integration elements were used to model SNTT Base-1 specimen with a crack length of $0.1485 \mathrm{inch}$. The fractur torque is at $398.2 \mathrm{lbf}$-in. The deformed FEM model upon failure and the estimated von Miss stress contours are shown in Figure 38, where significant crack front blunting was also observed. The Abaqus J-contour integral routine with 9-contours option was used to determine $\mathrm{J}$ value. Near middle layer's J-contour data were used to estimate $\mathrm{J}_{\mathrm{Q}}$ for SNTT 304 Base-1 specimen upon final fracture; which results in $\mathrm{J}_{\mathrm{Q}}=1618 \mathrm{lb} /$ in $\left(283.4 \mathrm{KJ} / \mathrm{m}^{2}\right)$. 


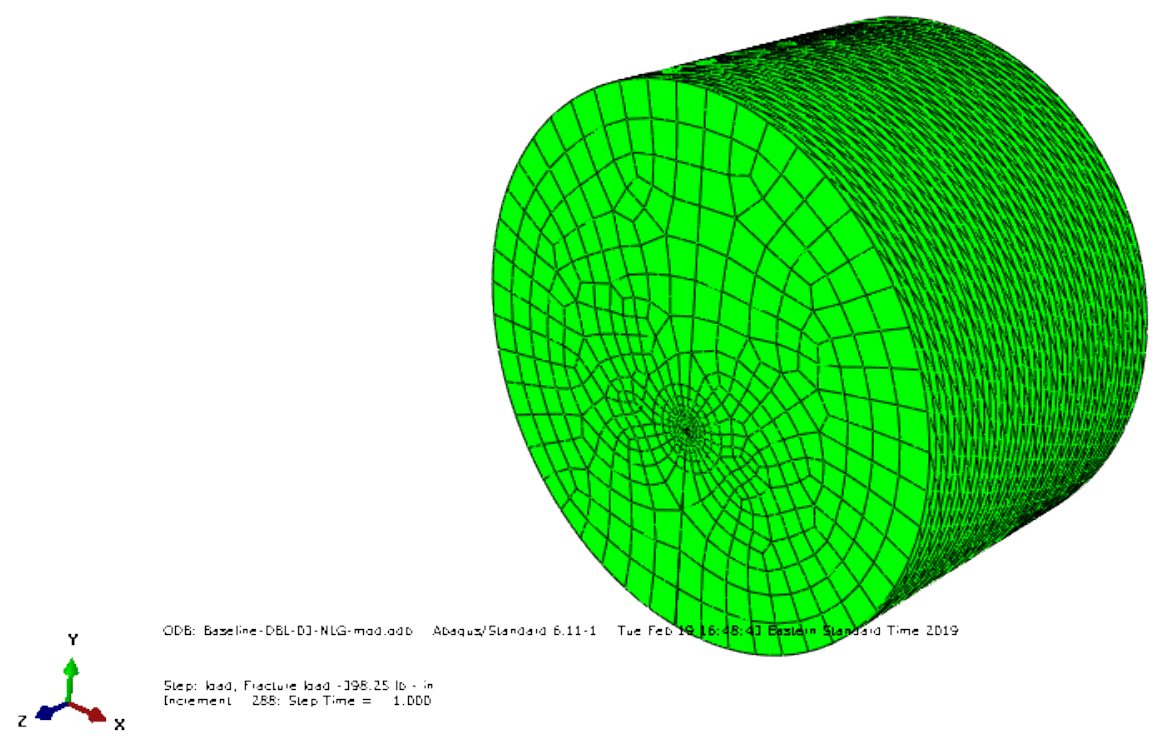

Figure 37. Finite element model for SNTT Base-1 specimen test simulation.
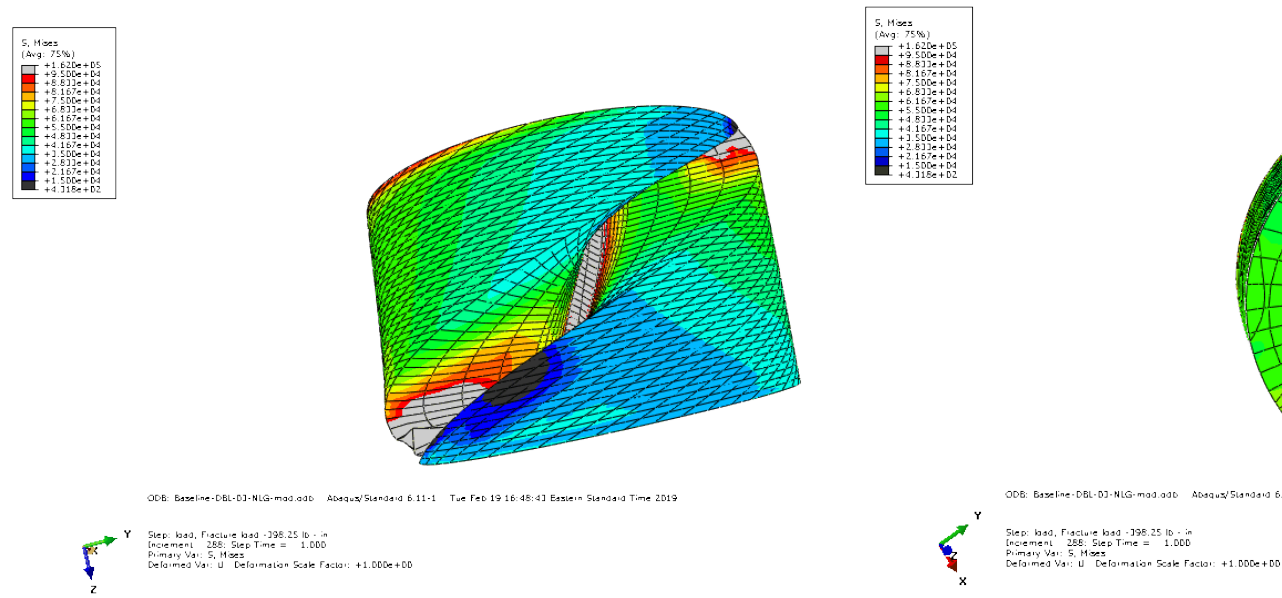

Figure 38. (Left) Full model FEM deformation and von-Miss stress profile, (Right) Deformation and von Miss stress profiles at near middle layer of finite element model, where significant crack front blunting was observed. 


\subsection{Comparison between SNTT and CT Tests Results for Fracture Toughness Evaluation}

The comparison of SNTT 304/308 weld fractur fracture toughness and that obtained from conventional CT test [26] are illustrated in Table 5; where SNTT weld test samples uncertainty bond evaluation was performed on the targeted a/D in the range of 0.40 to 0.42 . Small two-sigma uncertainty bond of SNTT approach compared to that of CT test results is primary due to the self-consistent fracture torques observed from the SNTT fracture test results as shown in Table 4.

Table 5 Summary of fracture toughness obtained from SNTT test and CT test results

\begin{tabular}{|l|l|l|l|l|l|l|l|l|}
\hline $\begin{array}{l}\text { Test } \\
\text { Method }\end{array}$ & Material & Condition & Temperature & $\begin{array}{l}\text { Mean } \mathrm{J}_{\mathrm{IC}} / \\
\text { or } \mathrm{J}_{\mathrm{Q}}\end{array}$ & $\begin{array}{l}\text { Mean } \mathrm{J}_{\mathrm{IC}} / \\
\text { or } \mathrm{J}_{\mathrm{Q}}\end{array}$ & $\begin{array}{l}95 \% \\
\text { Bond }\end{array}$ & $\begin{array}{l}95 \% \\
\text { Bond }\end{array}$ & $\begin{array}{l}\text { Type of } \\
\text { Sample }\end{array}$ \\
\hline & & & $\mathrm{F}$ & $\mathrm{lb} / \mathrm{in}$ & $\mathrm{KJ} / \mathrm{m}^{2}$ & $\mathrm{lb} / \mathrm{in}$ & $\mathrm{KJ} / \mathrm{m}^{2}$ & \\
\hline CT & 304 & Base metal & $70 \mathrm{~F}$ & 3837.0 & 672.0 & 1227.0 & 215.0 & Base \\
\hline SNTT & 304 & Base metal & $70 \mathrm{~F}$ & 1618.0 & 283.3 & N/A & N/A & Base \\
\hline CT & $304 / 308$ & SAW & $70 \mathrm{~F}$ & 839.4 & 147.0 & 382.5 & 67.0 & Weld \\
\hline SNTT & $304 / 308$ & SAW & $70 \mathrm{~F}$ & 802.9 & 140.6 & 50.0 & 8.8 & Weld \\
\hline SNTT & $304 / 308$ & SAW & $70 \mathrm{~F}$ & 717.3 & 126.0 & 6.8 & 1.2 & HAZ \\
\hline
\end{tabular}




\section{CONCLUSIONS}

A new torsion bar testing method, SNTT, has been developed for estimating the opening mode fracture toughness, KIC. A round-bar specimen having a spiral $V$-groove line at $45 \mathrm{deg}$ pitch is used, subjected to pure torsion. Commercially available mullite ceramic, 7475-T7351 aluminum, and A302B steel were tested. The $K_{I C}$ values for the materials were estimated with the aid of a three-dimensional finite element analysis based on the fracture load and measured crack length data. Predicted values derived from SNTT were compared with ORNL CT data, those reported by vendors, and those available in the open literature. The agreement between the SNTT and the reported data is remarkable, in view of possible material variation, inhomogeneity, and anisotropy, indicating the proposed method is a reliable technique. Due to its contribution to the advanced fracture mechanics, SNTT won a 2002 R\&D 100 Award.

The unique features of the proposed testing method are:

- The stress and strain fields under pure torsion of a circular bar are a function of radius only and are the same everywhere along the notch line. The length of the spiral crack is equivalent to the thickness of a compact tension specimen. The size effect that normally is a serious concern in compact type specimens is virtually eliminated in SNTT specimen. Therefore, miniature specimens can be used effectively with the SNTT method.

- Fracture failure in combined mixed-mode (Mode I and Mode III) pertinent to pressure vessel piping systems can be tailored for simulation study by varying the pitch angle of the starting notch line or alternatively having the standard specimen subjected to various combinations of loads in tension and torsion.

- Due to the controllable crack growth behavior and miniaturization of SNTT characteristics, SNTT has a potential for use in determining the $K I C$ values of interface of inhomogeneous materials interfaces and welding properties of HAZ.

Detailed studies show that the evolutions of compliance and fracture resistance of the SNTT sample during the fatigue crack growth process can be unified together irrespective of specimen sizes and material types. In addition to the special features of small volume specimen and ease of testing with the SNTT method, the independence of size effect is in rigorous analytical results for this testing method. The evolution of compliance and fracture resistance in the SNTT process has also been presented with simple governing equations using the ratios of crack lengths over the cylindrical diameter.

Based on the measured torques and rotation angles, the penetrated crack depth can be obtained through developed compliance governing equation, after the fatigue pre-crack procedures completed. Therefore, it is possible to control the crack penetration depth of SNTT experiment via monitoring the applied torques and rotation angles, which can be easily implemented by industrial communities.

In the past SNTT technology has also been successfully applied to investigate the fracture behavior of X52 and X80 steels and the X52 welded materials used for hydrogen infrastructures. The current study in supporting Sandia SNF Dry Storage Mock-up Canister Program is the first attempt of applying SNTT to the highly ductile stainless steel and the associated weld materials. The SNTT test results indicate that SNTT method is a reliable test approach with good repeatability in applying to SS304 steel and SS304/308 weld material. The estimate $\mathrm{J}_{\mathrm{Q}}$ upon fracture for the baseline SS304 steel is at $1618 \mathrm{lb} / \mathrm{in}$. The estimate $\mathrm{J}_{\mathrm{Q}}$ upon fracture for the SS304/308 weld from HAZ and weld specimens are $720 \mathrm{lb} /$ in and $850 \mathrm{lb} /$ in, respectively. 


\section{REFERENCE}

1. D.G. Enos and C.R. Bryan, Final Report: Characterization of Canister Mockup Weld Residual Stress. Sandia National Laboratory, November 22, 2016. FCRD-UFD-2016-000064.

2. Nuclear Waste Technical Review Board (NWTRB). (2010). Evaluation of the technical basis for extended dry storage and transportation of used nuclear fuel. Arlington, VA. Nuclear Waste Technical Review Board.

3. Hanson, B., Alsaed, H., Stockman, C., Enos, D., Meyer, R. and Sorenson, K. (2012). Gap analysis to support extended storage of used nuclear fuel, FCRD-USED-2011-000136. U.S. Department of Energy.

4. NRC. (2012a). Identification and Prioritization of the Technical Information Needs Affecting Potential Regulation of Extended Storage and Transportation of Spent Nuclear Fuel. Draft for comment. U.S. NRC.

5. Potential Chloride Induced Stress Corrosion Cracking of Austenitic Stainless Steel and Maintenance of Dry Cask Storage System Canisters. Washington, D.C.: U.S. NRC.

6. Extended Storage Collaboration Program (ESCP) Progress Report and Review of Gap Analyses. Palo Alto, CA.

7. Enos, D. G., Bryan, C. R. and Norman, K. M. (2013). Data Report on Corrosion Testing of Stainless Steel SNF Storage Canisters, FCRD-UFD-2013-000324. U.S. DOE, Office of Used Nuclear Fuel Disposition.

8. Bryan, C. R. and Enos, D. G. (2015). Analysis of Dust Samples Collected from an Unused Spent Nuclear Fuel Interim Storage Container at Hope Creek, Delaware, SAND2015-1746. Albuquerque, NM. Sandia National Laboratories.

9. Stainless Steels Properties - How to Weld Them and Where to use Them. The Lincoln Electric Company. http://www.lincolnelectric.com/assets/global/Products/Consumable_StainlessNickelandHighA 1loy-Excalibur- Excalibur316316L-17/c64000.pdf

10. http://www.lincolnelectric.com/assets/global/Products/Consumable_StainlessNickelandHighAlloyLincolnweld-Lincolnweld308308L/c61024.pdf.

11. Wang, J.-A., et.al., 2000. Using torsional bar testing to determine fracture toughness, Fatigue \& Fracture of Engineering Materials \& Structures Journal, 23, 917-927.

12. Wang, J.-A., Liu, K., “A New Approach to Evaluate Fracture Toughness of Structural Materials,” Journal of Pressure Vessel Technology, Vol. 126, pp 534-540, 2004.

13. Wang, J.-A., et.al., 2006. A new approach for evaluating thin film interface fracture toughness, Journal of Materials Science and Engineering A, 426 332-345.

14. Wang, J.-A., Kidane, A., "A new Approach to Determine the Quasi-static and Dynamic Fracture Toughness of Materials," SEM XII International Congress \& Exposition on Experimental \& Applied Mechanics, Orange County/Costa Mesa, June 11-14, 2012.

15. Bayles, R., Singh, R., Knight, S., Wang, J.-A., "Evaluating Stress-Corrosion Cracking Susceptibility Using a Torsion Test," 2005 ASME Pressure Vessel Piping Conference, July 17-21, 2005, Denver, Colorado.

16. Wang, J.-A., “Oak Ridge National Laboratory Spiral Notch Torsion Test System,” Journal of Practical Failure Analysis, Vol. 3(4) August 2003.

17. Wang, J.-A., Liu, K., 2008. An innovative technique for evaluating fracture toughness of graphite materials, Journal of Nuclear Materials, 381, 77-184.

18. Wang, J.-A., Liu, K., Naus, D., 2010. A new test method for determining the fracture toughness of concrete materials, Journal of Cement and Concrete Research, 40, 497-499. 
19. Tan, T., Ren, F., Wang, J.-A., et.al., 2013. Investigating fracture behavior of polymer and polymeric composite materials using spiral notch torsion test, Journal of Engineering Fracture Mechanics, 10, 109128.

20. Ren, F., Wang, J.-A., Bertelsen, W., "Fractographic study of epoxy materials fractured under mode I loading and mixed mode I/III loading”, Materials Science and Engineering A, Vol. 532, p. 449-455, 2012.

21. Bayles, R., King, S., Wang, J.-A., "Application of Disc Compact Tension Formulas to Compliance and K-Calibration of Spiral Notch Torsion Test Specimens," 6th International Aircraft Corrosion Workshop, August 24-27, 2004 at the Holiday Inn Select, Solomons, Maryland.

22. Wang, J.-A., Wright, I., et.al., "Interface Fracture Toughness Evaluation for MA956 Oxide Film," Proceeding of 2005 ASM International Surface Engineering Congress, pp 80-89, August 1-3, 2005, St. Paul, Minnesota.

23. Zhang, W., Feng, Z., Wang, J.-A., "Measurement of Fracture Toughness of Materials with Non-uniform Microstructure by Spiral Notch Torsion Test," 2010 ASME PVP Conference, July 18-22, 2010, Washington.

24. Wang, J.-A., Ren, F., Tan, T., Liu, K., "The development of in situ fracture toughness evaluation techniques in hydrogen environment," International Journal of Hydrogen Energy, 40 (2015) p.p. 20132024, January 2015.

25. Jy-An Wang, Ting Tan, "A method for evaluating the fatigue crack growth in spiral notch torsion fracture toughness test," Archived of Applied Mechanics Journal, DOI: 10.1007/s00419-018-1398-2, May 2018.

26. W. J. Mills, "Fracture toughness of type 304 and 316 stainless steels and their welds," International Materials Reviews, 42:2, 45-82, DOI: 10.1179/imr.1997.42.2.45. 